\title{
ULTRASOUND-MICROBUBBLE COMBINED TREATMENT WITH VINCA ALKALOIDS IN PROSTATE CANCER CELLS
}

\author{
By \\ Aren Gharabeiki \\ B.Sc. Ryerson University, 2015 \\ Toronto, Canada \\ A thesis presented to Ryerson University \\ in partial fulfillment of the \\ requirements for the degree of \\ Master of Science \\ In the Program of \\ Biomedical Physics \\ Toronto, Ontario, Canada, 2019 \\ (C) Aren Gharabeiki 2019
}




\section{AUTHOR'S DECLARATION}

I hereby declare that I am the sole author of this thesis. This is a true copy of the thesis, including any required final revisions, as accepted by my examiners.

I authorize Ryerson University to lend this thesis to other institutions or individuals for the purpose of scholarly research.

I further authorize Ryerson University to reproduce this thesis by photocopying or by other means, in total or in part, at the request of other institutions or individuals for the purpose of scholarly research.

I understand that my thesis may be made electronically available to the public.

Aren Gharabeiki 


\title{
$\underline{\text { ABSTRACT }}$
}

\section{ULTRASOUND-MICROBUBBLE COMBINED TREATMENT WITH VINCA ALKALOIDS IN PROSTATE CANCER CELLS}

\author{
Aren Gharabeiki \\ Master of Science, Biomedical Physics \\ Ryerson University, 2019
}

Therapeutic efficacy of chemotherapy is highly dependent on the ability to deliver drug molecules across tissue and cellular barriers. Ultrasound stimulated microbubbles (USMB) have been shown to enhance the delivery and cytotoxicity of various classes of chemotherapeutic agents. Here, the application of USMB in combination with the chemotherapeutic class vinca alkaloids is investigated. Specifically, vinorelbine tartrate (VRL) and vinblastine sulfate (VBL) of the vinca alkaloid class, which to the best of our knowledge have not been reported in combination with USMB, were used in this study. Cell viability analysis demonstrated that USMB does not enhance the cytotoxicity of either drug. VRL+USMB showed to have an additive response in cell death, whereas VBL+USMB resulted in an additive effect at a low peak negative pressure, and antagonistic at higher pressures. This work suggests that the mechanism of uptake is an important factor in determining the effectiveness of a chemotherapy drug with USMB treatment. 


\section{ACKNOWLEDGEMENTS}

First and foremost, I would like to thank my supervisor, Dr. Raffi Karshafian for walking alongside me every step of the way, and improving my perspective not only scientifically, but in all aspects of life.

I would like to thank my committee members Dr. Michael Kolios, Dr. Costin Antonescu and Dr. Warren Lee for sharing their wealth of knowledge and expertise with me.

I would also like to thank my fellow lab mates Mathew Rajic, Rahul Misra, Charlotte Ferworn, Victoria Bulycheva and for my former lab mate Shadab Momin for helping me grow and growing with me. I would like to especially thank Mathew for being there for me through all the ups and downs, especially when an up seemed nowhere in sight.

To all the Biomedical Physics and St. Michael's Hospital staff and students I've had the pleasure of befriending, thank you for the friendly faces and the countless memories.

Finally, to my family and friends, thank you for the unconditional love and support, without which I can truly say I wouldn't be here without. And to Kathrine, for being my rock. 


\section{Table of Contents}

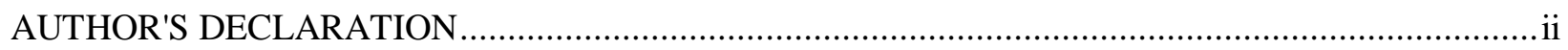

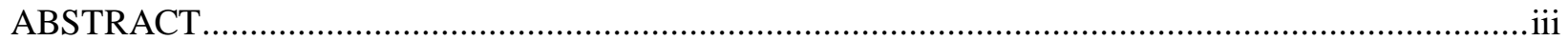

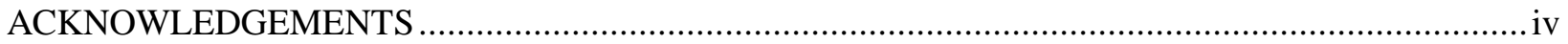

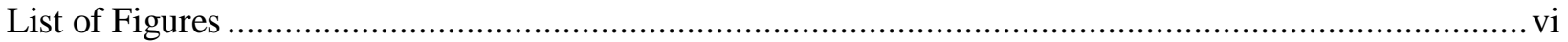

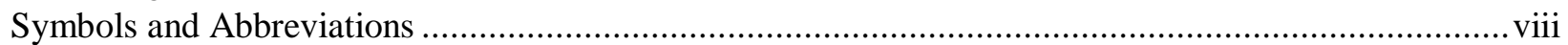

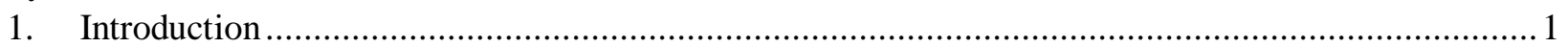

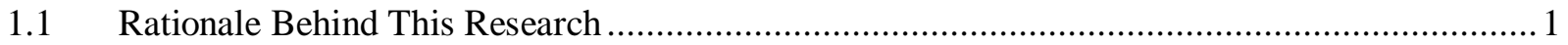

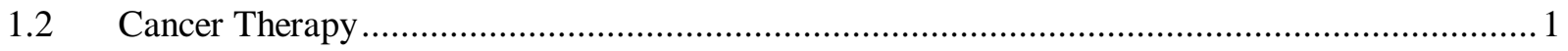

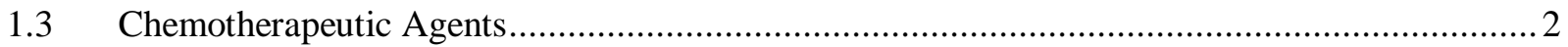

1.3.1 Microtubule-Active Chemotherapy Drugs................................................................... 3

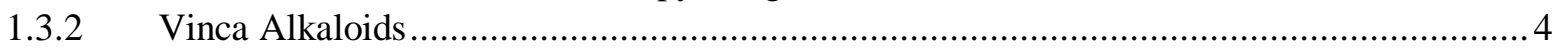

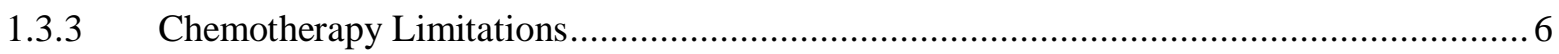

$1.4 \quad$ Ultrasound Mediated Microbubble Therapy ………………………………………….....

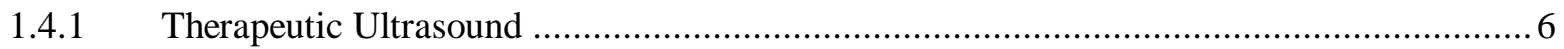

1.4.2 Microbubbles in Ultrasound Field .........................................................................

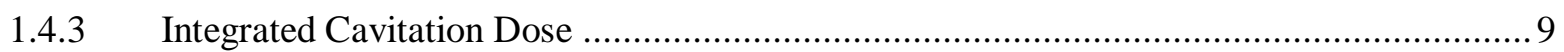

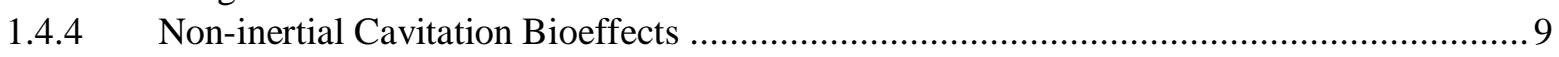

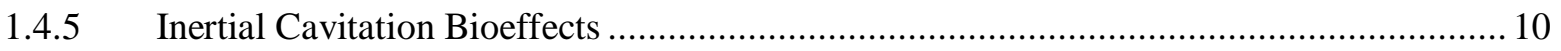

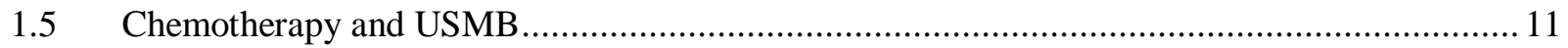

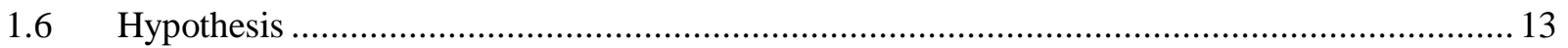

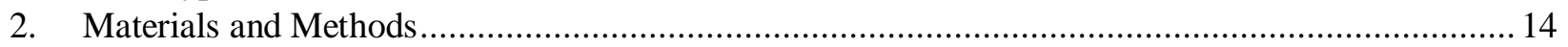

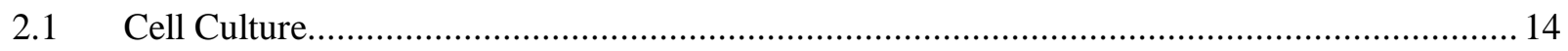

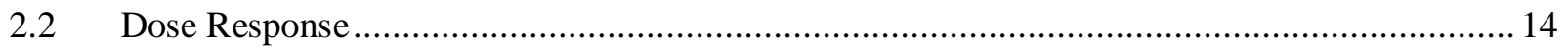

2.3 Cell Viability with XTT Assay ……………………………………………………..... 15

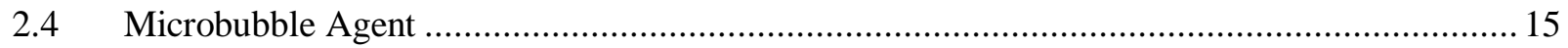

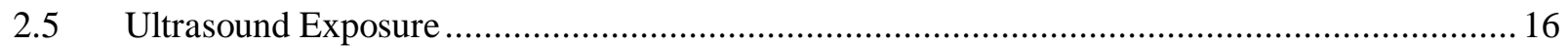

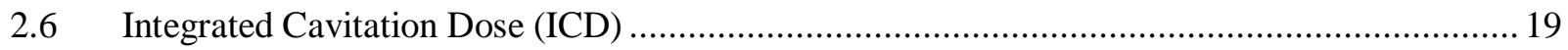

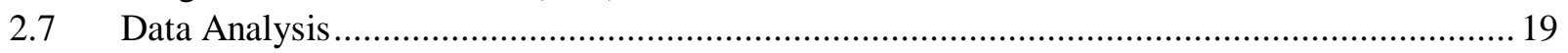

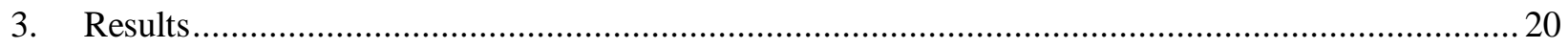

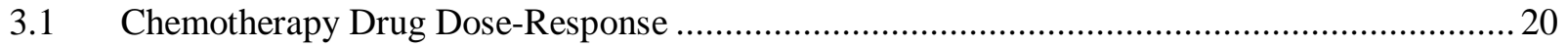

3.2 Combined Treatment with Vinca Alkaloids and USMB ………………………………........22

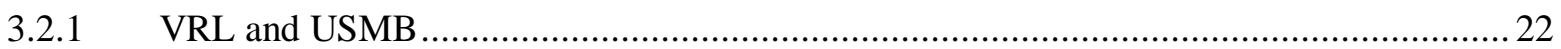

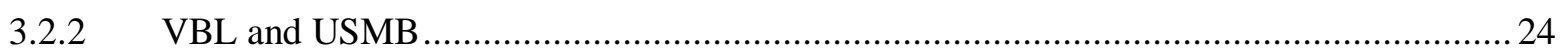

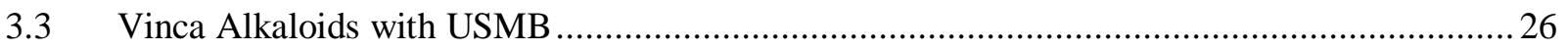

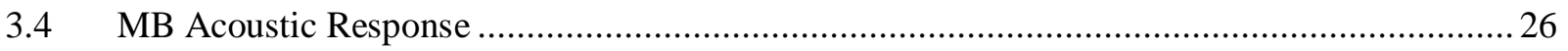

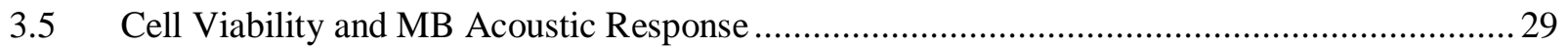

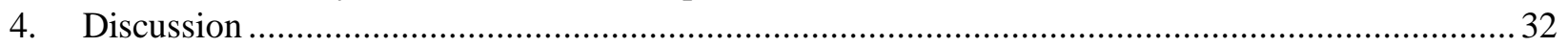

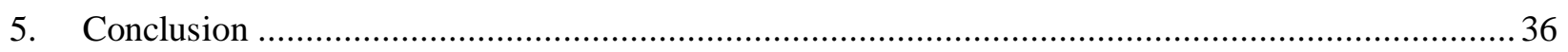

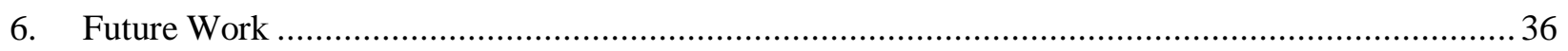

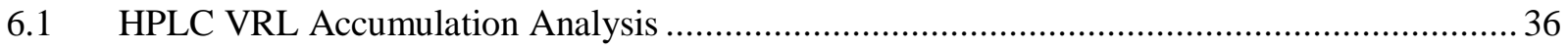

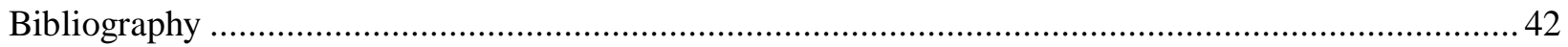




\section{$\underline{\text { List of Figures }}$}

Figure 1-1(a) $\alpha$ - and $\beta$-tubulin heterodimers and the structural makeup of microtubules. (b) Binding sites of vinca alkaloids and other microtubule targeting agents. Adapted from (Krause, 2019)

Figure 1-2 Behaviour of MBs in the presence of (a) low ultrasound pressures (b) high ultrasound pressures. (Adapted from Mo, Coussios, Seymour, \& Carlisle, 2012).

Figure 2-1 Schematic representation of treatment setup. Transmitting and passive at transducers perpendicular orientation, both facing treatment chamber. (Adapted from Shadab Momin, 2016)

Figure 3-1 Dose-response of PC3 cells treated with increasing concentration of vinorelbine tartrate (VRL). Dose-response range tested 50-250 $\mu \mathrm{M}$. Viability determined using XTT assay. Cells were incubated for 4 hours after exposure. Normalized with respect to untreated control $\mathrm{n}=9$ independent samples.

Figure 3-2 Dose-response of PC3 cells treated with increasing concentration of vinblastine sulfate (VBL). Dose-response ranged tested $100-250 \mu \mathrm{M}$. Viability determined using XTT assay. Cells were incubated for 4 hours after exposure. Normalized with respect to untreated control. $n=9$ independent samples.

Figure 3-3 Cell viability of combination treatment of PC3 cells treated with USMB in the presence and absence of $100 \mu \mathrm{M}$ vinorelbine tartrate (VRL). Cells were incubated for 4 hours after treatment. Viability determined using XTT assay. (a) All conditions normalize d with respect to untreated control. (b) USMB conditions normalized with respect to untreated control, USMB - VRL conditions normalized with respect to VRL alone. USMB treatment exposure conditions: $1.0 \mathrm{MHz}, \mathrm{PDP}=8$ cycles, $\mathrm{PRP}=2 \mathrm{~ms}$, exposure time $=30 \mathrm{~s}, \mathrm{PNP}=370,570,770$ $\mathrm{kPa} . \mathrm{n}=9$ independent samples.

Figure 3-4 Cell viability of combination USMB treatment of PC3 cells treated in the presence and absence of $150 \mu \mathrm{M}$ vinblastine sulfate (VBL). Viability determined using XTT assay. (a) Conditions normalized with respect to untreated control. (b) USMB alone conditions normalized with respect to untreated control, VBL+USMB conditions normalized with respect to VBL alone. USMB treatment exposure conditions: Acoustic frequency $=1.0 \mathrm{MHz}, \mathrm{PDP}=8$ cycles, $\mathrm{PRP}=2 \mathrm{~ms}$, exposure time $=30 \mathrm{~s}, \mathrm{PNP}=370,570,770 \mathrm{kPa} . \mathrm{n}=9$ independent samples. 
Figure 3-5 ICD of MB acoustics as a function of increasing PNP. Acoustic frequency $=1.0$ $\mathrm{MHz}, \mathrm{PDP}=8$ cycles, $\mathrm{PRP}=2 \mathrm{~ms}$, exposure time $=30 \mathrm{~s} . \mathrm{n}=9$ independent samples.

Figure 3-6 Spectral energies generated by Definity® MBs at (a) $370 \mathrm{kPa}$ PNP (b) $570 \mathrm{kPa}$ PNP

(c) $770 \mathrm{kPa}$ PNP.

Figure 3-7 Cell viability with respect to ICD for (a) VRL (b)VBL. All values normalized to untreated control. Acoustic frequency $=1.0 \mathrm{MHz}, \mathrm{PDP}=8$ cycles, $\mathrm{PRP}=2 \mathrm{~ms}$, exposure time $=$ $30 \mathrm{~s}, \mathrm{PNP}=370,570,770 \mathrm{kPa} . \mathrm{n}=9$ independent samples. .30

Figure 3-8 Cell viability with respect to ICD. Trendline shown for USMB alone and drug + USMB at $370-770 \mathrm{kPa}$ PNP range for (a) VRL (b) VBL. Acoustic frequency $=1.0 \mathrm{MHz}$, PDP $=8$ cycles, $\mathrm{PRP}=2 \mathrm{~ms}$, exposure time $=30 \mathrm{~s}, \mathrm{PNP}=370,570,770 \mathrm{kPa} . \mathrm{n}=9$ independent samples

Figure 6-1 VRL spectrogram. Detected at $215 \mathrm{~nm}$. Obtained using a gradient elution profile from HPLC measurement. Measured in milli-Absorbance units. 38

Figure 6-2 Calibration curve for increasing concentrations of VRL in 10\% SDS. Detected at 215 $\mathrm{nm}$ from HPLC measurement. Measured in Peak Absorbance

Figure 6-3 Calibration curve for increasing concentrations of VRL in RPMI media. Detected at $215 \mathrm{~nm}$ from HPLC measurement. Measured in Peak Absorbance.

Figure 6-4 Intracellular (pellet) and supernatant VRL mass as a function of increasing exposed VRL concentration.

Figure 6-5 Intracellular and supernatant VRL mass of samples exposed to $100 \mu \mathrm{M}$ VRL and 700 $\mathrm{kPa}$ PNP USMB as a function of increasing time where $1=5 \mathrm{~min}, 2=30 \mathrm{~min}, 3=1 \mathrm{hr}, 4=2 \mathrm{hr}$, $5=3 \mathrm{hr}$, and $6=4 \mathrm{hr}$. 


\section{Symbols and Abbreviations}

$\begin{array}{ll}\text { USMB } & \text { Ultrasound Microbubble } \\ \text { US } & \text { Ultrasound } \\ \text { MB } & \text { Microbubble } \\ \text { PNP } & \text { Peak Negative Pressure } \\ \text { PRP } & \text { Pulse Repetition Period } \\ \text { PDP } & \text { Pulse Duration Period } \\ \text { PBS } & \text { Phosphate Buffered Saline } \\ \text { FDA } & \text { Food and Drug Administration } \\ \text { FBS } & \text { Fetal Bovine Serum } \\ \text { PCD } & \text { Passive Cavitation Detection } \\ \text { ICD } & \text { Integrated Cavitation Dose } \\ \text { IFP } & \text { Interstitial Fluid Pressure } \\ \text { FFT } & \text { Fast Fourier Transformation } \\ \text { PDS } & \text { Power Density Spectrum } \\ \text { VRL } & \text { Vinorelbine Tartrate } \\ \text { VBL } & \text { Vinblastine Sulfate } \\ \text { HPLC } & \text { High Performance Liquid Chromatography } \\ \text { SDS } & \text { Sodium Dodecyl Sulfate }\end{array}$




\section{Introduction \\ 1.1 Rationale Behind This Research}

Anticancer agents have been shown to successfully kill cultured tumour cells, however in vivo, their efficacy is reduced due to the tumour microenvironments, and abnormal tumour vasculature which is usually associated with lower drug bioavailability (Qin, Wang, \& Willmann, 2016; Lozano et. al.. 2012). Ultrasound and microbubble exposure has been shown to enhance the accumulation of fluorescent molecules, gene products and chemotherapeutic drugs within cells (Newman \& Bettinger, 2007; Shapiro et al., 2016). This phenomenon of transiently permeabilizing cells for enhanced uptake is broadly referred to as sonoporation and has been shown widely in vitro and in vivo, laying the groundwork for potential clinical applications due to its safe noninvasive, non-ionizing and cost-effective translational capabilities (Qin, Wang, \& Willmann, 2016). The focus of this study is to assess the capabilities of ultrasound and microbubble (USMB) therapy with a widely used chemotherapy class, vinca alkaloids. To the best of our knowledge, drugs of this class have never been used in USMB combined treatments. Specifically, this work will aim to evaluate the potential in vitro therapeutic aspects of USMB in combination with two vinca alkaloid drugs, vinorelbine tartrate and vinblastine sulfate.

\subsection{Cancer Therapy}

In cancer model studies, effectiveness of in vivo treatments significantly decrease due to the barriers of drug delivery in tumour microenvironments (Lozano et. al., 2012). These solid tumours consist of rapidly reproducing tumour cells, its stroma and vasculature with characteristics that differ from that of normal tissue. Disorderly vessels can have chaotic spatial distribution and 
microvessel length and diameter, causing them to be porous and leaky. This allows the diffusion of relatively larger particles up to a few hundred nanometers to pass through (Hobbs et. al., 1998). Because of the nature of cancerous structures, tumours often do not have the functional lymphatic drainage system that normal tissues do. The effect of high vascular permeability combined with the weak lymphatic drainage leads to an increase in interstitial fluid pressure (IFP), limiting the transport of particles in the interstitium (Boucher et. al., 1990). Vessels can also be forced apart by tumour proliferation, leading to tumour cells being separated from blood vessels by distances over 100 micron (Minchinton and Tannock, 2006). Due to the combination of high IFP, transportation complications and increased vessel-to-cell distance, drug treatments can be severely handicapped and only a limited amount of therapeutic agents can potentially reach and enter tumour cells.

\subsection{Chemotherapeutic Agents}

The optimization of a chemotherapy treatment requires an understanding of the combined principles of tumour biology, cellular dynamics, pharmacology and drug resistance (Page \& Takimoto, 1998). Chemotherapy agents are often categorized according to their chemical structure and function. Although there are over 100 different chemotherapy drugs, they can be classified into categories which include: alkylating agents, antimotabolites, antitumour antibiotics, plant alkaloids, topoisomerase inhibitors, and miscellaneous agents (Cancer Australia, "Antineoplastic Agents", 2014). Vinca alkaloids fall in the plant alkaloids category are characterized by their ability to bind to the microtubule proteins of the cell, notably at the mitotic stage of the cell cycle. 


\subsubsection{Microtubule-Active Chemotherapy Drugs}

Microtubules are polymers found all throughout the cell and are key contributors to cell structure maintenance, protein trafficking, chromosomal segregation, and mitosis (Stanton, Gernert, Nettles, $\&$ Aneja, 2011). They are made up of two proteins known as $\alpha$-tubulin and $\beta$-tubulin that form together into a dimer complex. These dimers form long polymers chains that assemble into hollow tubes roughly $25 \mathrm{~nm}$ in diameter (Gelfand \& Bershadsky, 1991). They are responsible for the robust cellular cytoskeleton, however they are highly dynamic polymers and continuously alternate between periods of growth and shortening. This dynamic reorganization allows for the formation of the bipolar mitotic apparatus commonly known as the mitotic spindle. The spindles function to separate the replicated chromosomes accurately into two daughter cells during mitosis. This key characteristic is highly favourable for anticancer agents that target microtubules due to the rapidly dividing nature of cancer cells (Jordan, Hadfield, Lawrence, \& McGown, 1998; Giannakakou, Sackett, \& Fojo, 2000).

Current clinical treatment regimens include two main classes of microtubule-active compounds, the taxanes and the vinca alkaloids. They are commonly not used for the same cancer types, and can be conceptually thought of as microtubule stabilizers (taxanes) and destabilizers (vinca alkaloids) (Jordan, Hadfield, Lawrence, \& McGown, 1998). The two classes also have slightly different binding sites on the $\beta$-tubulin dimer in microtubules (Rowinsky \& Donehower, 1991). Both drugs from the taxane class, docetaxel and paclitaxel, have been used in in vitro and in vivo studies with USMB treatment. In current literature, no vinca alkaloid class drug has been combined alongside USMB therapy. This study aims to investigate the potential of USMB in enhancing the therapeutic effect of vinca alkaloid drugs. 


\subsubsection{Vinca Alkaloids}

Vinca alkaloids are a naturally occurring and semi-synthetic class of chemotherapy drug isolated from the periwinkle plant Catharanthus roseus G. Don. that have been extremely important in cancer therapy for decades (Jordan et al., 1991; Sottomayor \& Barcelo, 2006; Jordan \& Wilson, 2004; Rowinsky, 2003). This class has been used to treat Hodgkin lymphoma, breast cancers, small lung cancer and prostate cancers among other cancers (Goodman et al., 2011; Abratt et al., 2004). These drugs are considered cell-cycle specific and operate mainly by targeting cells in the G2/M phase of the cell cycle (Jordan et al., 1991; Simoens et al, 2008). They can affect both malignant and non-malignant cells but cancerous cells are more vulnerable due to their rapidly dividing nature. Cells that are not in the mitotic phase can still be targeted since microtubules are involved in many non-mitotic functions (Rowinsky, 2003). Other biochemical processes that may or may not be related to cytotoxic vinca alkaloid effects include protein and nucleic acid inhibition, membrane lipid alteration, and elevated levels of cyclic adenosine monophosphate (cAMP)(Rowinsky, 2003).

Originally, the two naturally occurring agents - vinblastine and vincristine - were isolated independently by two groups in the 1950's (Noble, Beer, \& Cutts, 1958; Johnson, Wright, Svoboda, \& Vlantis, 1960). Since then, several semi-synthetic analogues have been developed, including vinorelbine, vindesine and vinflunine (Jordan \& Wilson, 2004). Vinblastine, vincristine and vinorelbine are the three FDA approved chemotherapy agents currently used.

Vinca alkaloids are antimitotic agents in that they primarily target and bind to the tubulin dimers in the microtubules of the cells (Jordan \& Wilson, 2004). Microtubule binding of vinca alkaloids and other microtubule targeting agents is shown in Figure 1.1 Specifically, vinca alkaloids function by binding to the $\beta$-tubulin dimers to block the polymerization with $\alpha$ tubulin 
into microtubules (Goodman et al., 2011). They can rapidly and reversibly bind to both soluble and microtubule-associated tubulin (Gascoigne \& Taylor, 2009). It has been shown that two vinca alkaloid binding sites exist per mol of tubulin dimer and the binding to these sites with varying affinities based on whether the sites are situated along the microtubule ends or not (Downing, 2000). Approximately 16-17 high-affinity binding sites per microtubule exist at the end of each microtubule (Dumontet, 2000). Since these dimers are necessary for the mitotic spindle formation, cell division can be arrested in metaphase and duplicated chromosomes are unable to align along the division plate, causing them to disperse throughout the cytoplasm of the cell (Goodman et al., 2011). Overall, this mechanism is in contrast to the process observed for taxanes, which function by stabilizing the microtubules after polymer formation and prevent depolymerization (Jordan \& Wilson, 2004).
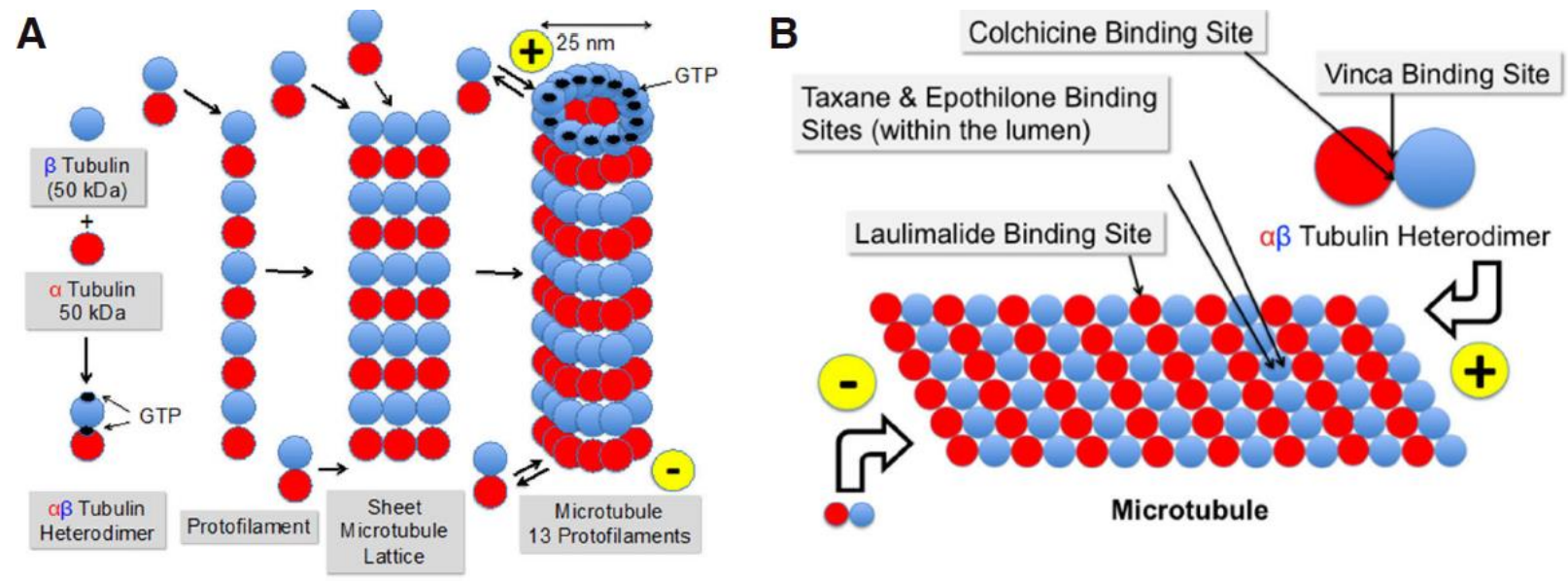

Figure 1-1(a) $\alpha$ - (red) and B- (blue) tubulin heterodimers and the structural makeup of microtubules. (b) Binding sites of vinca alkaloids and other microtubule targeting agents. Adapted from (Krause, 2019).

The exact mechanisms that cause cell death are not yet entirely understood, however it is plausible that similar mechanisms for the taxane class are involved, namely the actions of the $p$ 53, $b c l-2$ and $b c l-x$ genes and the corresponding gene products that trigger apoptosis when cellcycle and microtubule dynamic disruption occurs (Poruchynsky, Wang, Rudin, Blagosklonny, \& 
Fojo, 1998; Wang, Liu, Kreis, \& Budman, 1999. Vinca alkaloids can have varying individual patterns of clinical effectiveness, but they share similar resistance pathways. Their efficacy can be hindered by the multidrug resistance caused by the $m d r$ gene and its glycoprotein (Goodman et al., 2011).

Cellular uptake of vinca alkaloids was originally believed to be via energy and temperature dependent processes (Lengsfeld, Dietrich, \& Schultze-Maurer, 1982). To the contrary however, updated findings suggest that temperature-independent nonsaturable processes similar to those of simple diffusion account for the majority of the drug transport (Rahmani et al., 1994).

\subsubsection{Chemotherapy Limitations}

In general the clinical cytotoxic effects of chemotherapeutic agents tend to be both concentration and time dependent and vinca alkaloids are not an exception to that (Levêque \& Jehl, 1996). Because of this, vinca alkaloids can potentially benefit from a more effective delivery method that would both increase the bioavailability of the drug at the location of interest, as well as decrease the exposure of healthy tissue to unnecessary detriment. The addition of USMB treatment can potentially enhance the delivery - and thus cytotoxicity - of vinca alkaloids.

\subsection{Ultrasound Mediated Microbubble Therapy}

\subsubsection{Therapeutic Ultrasound}

Ultrasound is currently used in both diagnostic and therapeutic applications (Mo et al., 2012). Therapeutic applications include the use of high-intensity focused ultrasound (HIFU) for tissue thermal ablation (Dubinsky 2008, Ter Haar \& Coussios, 2007), lithotripsy for the breakdown of kidney and gall stones (Sokolov, Bailey, \& Crum, 2003), and phacoemulsification for cataract treatment (Liu et al., 2007; Zeng et al., 2008). Low intensity ultrasound can be used for bone and 
tissue (Rubin, 2001) repair and for stimulating the reversible disruption of the blood-brain barrier (McDannold, Vykhodtseva, \& Hynynen, 2008; Liu, Fan, Ting, \& Yeh, 2014). Therapeutic ultrasound can also be used in targeted drug delivery, importantly for localized drug uptake for cancer therapy (Coussios \& Roy, 2008; Hernot \& Klibanov, 2008). The application for targeted enhanced drug delivery is the area of interest in this study.

\subsubsection{Microbubbles In an Ultrasound Field}

Microbubbles (MBs) are micron-sized gas-filled bubbles encapsulated by a surrounding shell and are currently clinically FDA and Health Canada approved for use as ultrasound contrast agents (UCAs) to improve ultrasound imaging contrast in the blood (De Jong, Bouakaz, \& Frinking, 2002; Von Bibra et al., 1999). Generally, these MBs have a mean diameter of 1-5 $\mu \mathrm{m}$ and are filled by inert gasses such as perfluorocarbon, sulfur hexafluoride or perflutren (Ibsen, Schutt, \& Esener, 2013). The surrounding shell consists of a layer such as lipid, polymer, albumin or protein. In this study the Definity® agent is used, which is comprised of a phospholipid shell and octofluoropropane $\left(\mathrm{C}_{3} \mathrm{H}_{8}\right)$ inert gas. According to the manufacturer, $98 \%$ of Definity ${ }^{\circledR}$ MBs are smaller than $10 \mu \mathrm{m}$ in size and comprise of a mean diameter of $1.1-3.3 \mu \mathrm{m}$ (Definity, 2008).

Microbubbles when present in the ultrasound field expand in the rarefactional phase of the wave and contract in the compressional phase due to compressibility of its gas-filled core. This alternating expanding and shrinking is a process known as cavitation (Lentacker, De Cock, Deckers, De Smedt, \& Moonen, 2014). The variables that dictate these oscillations include bubble factors such as material makeup and size, and ultrasound parameters such as frequency and acoustic pressure for example. 
Microbubble acoustic response is generally described in terms of non-inertial and inertial cavitation. At lower ultrasound pressures, MBs expand and contract in the non-inertial (stable) cavitation regime where they oscillate stably and typically remain intact throughout the exposure (Kang \& Yeh, 2012). (Figure 1.2a). In the high pressure ultrasound field, the MBs can undergo more violent oscillations as the rarefactional phase of wave allow the bubble to expand to a much greater extent and collapse in the ensuing compressional phases (Figure 1.2b). MBs are characterized to be in the inertial cavitation regime at this time and generate shock waves in the nearby bubble vicinity (Newman \& Bettinger, 2007). Both non-inertial and inertial oscillations can produce shear stresses on the cells in several ways, leading to physiological changes in barriers of blood vessels or on the surface of cell membranes, allowing for the uptake of foreign molecules (Zhao, Du, Lu, Jin, \& Ge, 2013; ter Haar, 2007).

(A) Stable or non-inertial cavitation

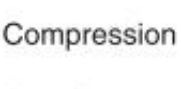

Rarefaction

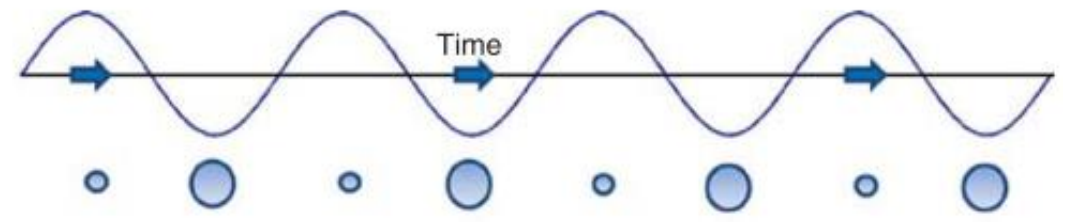

(B) Transient or inertial cavitation

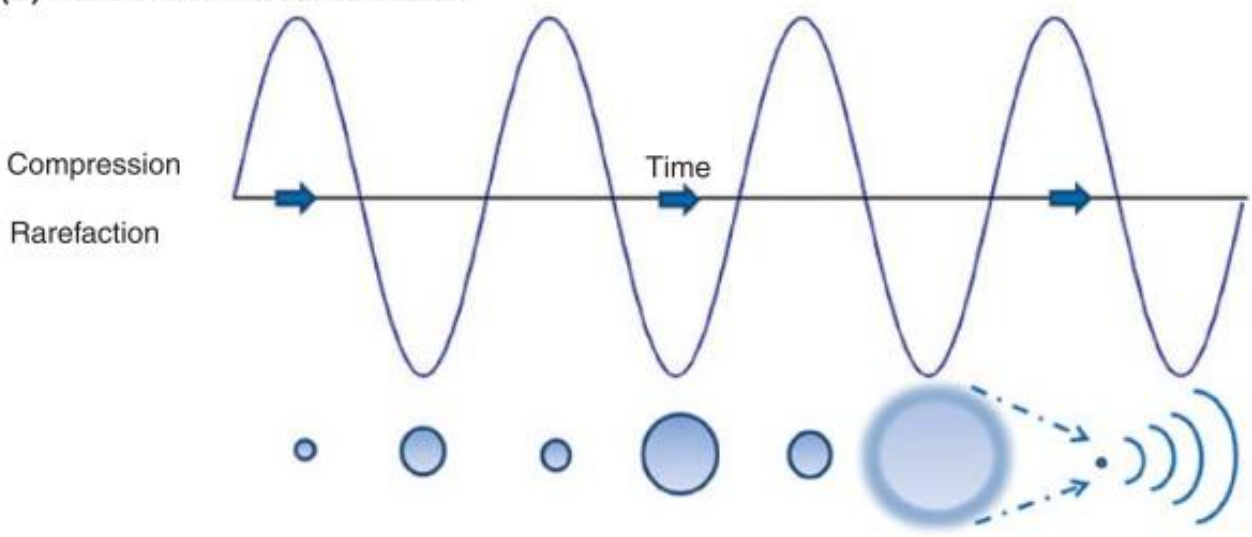

Figure 1-2 Behaviour of MBs in the presence of (a) low ultrasound pressures (b) high ultrasound pressures. (Adapted from Mo, Coussios, Seymour, \& Carlisle, 2012). 


\subsubsection{Integrated Cavitation Dose}

By passively listening to the scattered signals from oscillating MBs using passive cavitation detection (PCD), the MB activity can be analyzed. In this study, this analysis is done using integrated cavitation detection (ICD), where the time domain signals are converted to the frequency domain using a Fast Fourier Transform (FFT), and the areas of desired frequency bounds under the harmonics are summed to gain information about the type and magnitude of MB response. ICD allows the distinction of $\mathrm{MB}$ responses, particularly across the non-inertial and inertial threshold, where higher MB activity in the inertial regime results in higher harmonic response and in turn, higher ICD (King et al., 2010). By measuring this response, a comparison can be made to the bioeffects of treatment and act as both a level of analysis, as well as a quality control for future treatments.

\subsubsection{Non-inertial Cavitation Bioeffects}

Non-inertial bubble oscillations create flow around the MBs in a manner known as microstreaming (VanBavel, 2007). When this phenomenon occurs near cells, the shear stress can stimulate biological responses such as enhanced uptake (Wu \& Nyborg, 2008; Wu, Ross, \& Chiu, 2002). Two mechanisms are believed to facilitate the intracellular uptake of foreign molecules at these lower ultrasound intensities, small pore formation (Van Wamel, Bouakaz, Versluis, \& De Jong, 2004) and endocytosis (Meijering et al., 2009). Merijering et al. have demonstrated that pore formation has been the primary mechanism for smaller molecules ( $<155 \mathrm{kDa})$ (Meijering et al., 2009; Zhou, Kumon, Cui, \& Deng, 2009) whereas endocytosis is more prevalent for larger molecule uptake (>155 kDa). Single-cell experiments have generally shown that MBs must be in direct contact with the cell membrane for pore formation to take effect in the stable cavitation 
regime (Van Wamel, Bouakaz, Versluis, \& De Jong, 2004; van Wamel et al., 2006; Zhou, Yang, Cui, Ye, \& Deng, 2012). Greater bubble-cell distances are likely to lead to lower mechanical contact between MBs and the cell membrane, and lessen the microstreaming effects to the cell. The size of the transient pores formed during non-inertial cavitation are on the scale of tens to roughly one hundred nanometers (Zhou, Kumon, Cui, \& Deng, 2009).

The resealing process plays an important role in molecular accumulation because it allows for a transient and reversible window for enhanced uptake. This can be beneficial since it prevents the newly-entered molecules from escaping the cells and minimizes extensive biological cell disruptions. Resealing has been reported to occur on the order of milliseconds to seconds after initial ultrasound sonication has begun (Deng, Sieling, Pan, \& Cui, 2004; Zhou, Cui, \& Deng, 2008; Zhou, Kumon, Cui, \& Deng, 2009). Essentially, this suggests that the pores will exist so long as the MBs are present in the environment. The fast cell membrane resealing is confirmed by the sharp decline of intracellular calcium levels (Juffermans, Dijkmans, Musters, Visser, \& Kamp, 2006; Juffermans, Kamp, Dijkmans, Visser, \& Musters, 2008) and cell membrane potential returning to pre-exposure levels (Zhou, Shi, Cui, \& Deng, 2008).

\subsubsection{Inertial Cavitation Bioeffects}

When exposed to higher US pressures, MBs can undergo much more violent oscillations and collapse during the low pressure phase of the wave due to the heightened inertia caused by an influx of fluid. This inertial cavitation can lead to shock waves and jet formations. When near a surface such as a cell membrane, the collapse of a bubble can be asymmetrical and cause a liquid jet to penetrate towards the direction of the surface. The shear force exerted onto the cell can

perforate the membrane (Postema, Van Wamel, Lancée, \& De Jong, 2004; Leighton, 2007), 
allowing the uptake of both small and high molecular weight molecules. Pores on the membrane can be seen using scanning electron microscopy (SEM) and atomic force microscopy (AFM) imaging (Lentacker, De Cock, Deckers, De Smedt, \& Moonen, 2014). Larger pores can be formed by increasing ultrasound parameters such as pressure, treatment time, or pulse repetition frequency (Qiu et al., 2010).

\subsection{Chemotherapy and USMB}

Chemotherapeutic agents general lack specificity in cancer therapy, allowing high levels of toxicity in normal tissue. Furthermore, factors such as high tumour IFP can prevent the uptake of these drugs into the tumour region (Nomikou \& Mchale, 2010). Insonation of tumours with the presence of chemotherapeutic agents allow the potential for an enhancement of drug delivery while minimizing cytotoxic effects to normal tissues.

MBs are currently clinically approved for use as imaging contrast agents, however combined treatments with USMB therapy are not. Most work in the field is done using in vitro and in vivo models, with some studies translated to preclinical stages. Different types of USMB and chemotherapy studies have included USMB and free drug, USMB with drug-loaded MBs, USMB and drug-loaded micelles, USMB with drug-loaded micelles attached to MBs, USMB with drugloaded magnetic particles attached to MBs (Wood \& Sehgal, 2015). In an in vitro study for example, Escoffre et. al. (Escoffre, Piron, Novell, \& Bouakaz, 2011) used doxorubicin, an antineoplastic drug, in combination with USMB therapy and demonstrated that cell death was best enhanced above $600 \mathrm{kPa}$. This was found to be in true in both human glioblastoma (U-87MG) and breast cancer (MDA-MB-231) cell lines. The highest cell death was shown to be in the inertial cavitation regime for both SonoVue bubbles as well as polymer shelled MBs. This is in agreement 
with similar work that suggests higher ultrasound exposure conditions seem to result in a better treatment outcome (De Cock et al., 2015). In a separate study using the same drug, Hassan et al., showed - in a drug resistant human uterine carcinoma cells - that the order of insonation and doxorubicin resulted in a difference in sensitivity for the cells (Hassan et al., 2012). The authors demonstrated that either the cells could remain desensitized or become sensitized based on the treatment order. The antimitotic drug docetaxel has also been shown in an in vitro model in combination with USMB where the order of ultrasound treatment was applied both before and after drug exposure (Karshafian \& Almasri, 2010). A synergistic effect in cell death was seen in the combined therapy for both types of treatments. Successful translations to in vivo models have also been demonstrated, and often exhibit reduction in tumour growth (Liao et al., 2012; Sorace, Warram, Umphrey, \& Hoyt, 2012; Kotopoulis et al., 2014), as well as increased tumour drug accumulation (Cochran et al., 2011; Yan et al., 2013). Watanabe et al. for example, demonstrated in mice, a reduction in tumour size after a combined insonation treatment with cisplatin for both direct-to-tumour or intravenous injections of drug and MBs (Watanabe et al., 2008). Although not yet clinically feasible, this has allowed for the use of USMB as a combination treatment for drug delivery in preclinical human studies (Liu, Fan, Ting, \& Yeh, 2014; Liu et al., 2010; Dimcevski et al., 2016). In a phase 1 study of patients with pancreatic ductal adenocarcinoma, it was demonstrated that the combination of the chemotherapeutic agent, gemcitabine, with USMB using a commercially available clinical transducer resulted in no additional toxicity and no increased frequency of side effects (Dimcevski et al., 2016). The treatment also extended the medial patient survival from 8.9 to 17.6 months. 


\subsection{Hypothesis}

The hypothesis in this thesis is that USMB in combination with vinca alkaloid agents will enhance the cytotoxic effects in PC3 cancer cells in vitro.

This thesis objectives are to:

1. Determine the combined effect of USMB treatment with vinca alkaloid agents on cell viability.

2. Assess whether USMB induces a synergistic, additive or antagonistic effect when combined with vinca alkaloid drugs.

3. Determine if the outcome of USMB and vinca alkaloid treatment is contingent on MB activity. 


\section{Materials and Methods \\ 2.1 Cell Culture}

PC3 prostate cancer cells (ATCC, MD, USA) were chosen for this study as a relevant model. The cells were cultured in Roswell Park Memorial Institute (RPMI) 1640 media with 10\% (v/v) Fetal Bovine Serum (FBS) and 1\% (v/v) Penicillin-Streptomycin incubated at $37^{\circ} \mathrm{C}$ and $5 \%$ $\mathrm{CO}_{2}$. The cells were passaged at $80-90 \%$ confluence by way of $0.25 \%$ Trypsin-EDTA. For use in experiments, cells were trypsinized for 5 minutes after washing and centrifuged for 5 minutes at 200 g. Excess trypsin was removed and cells were resuspended in fresh media.

\subsection{Dose Response}

A dose response analysis of the cells were performed for both VRL and VBL agents (Pfizer Canada, Kirkland, QC, CA). $1.5 \cdot 10^{6}$ cells in $1.0 \mathrm{~mL}$ suspension were treated with increasing concentrations of either drug. Following exposure, the cell samples were incubated in 6-well plates for 4 hours at $37^{\circ} \mathrm{C}$ and $5 \% \mathrm{CO}_{2}$. Subsequently since some of the cells had adhered, the $1.0 \mathrm{~mL}$ of media were removed from the wells and stored in individual tubes, and the well-bottoms were trypsinized for 5 minutes ( $0.5 \mathrm{~mL}$ of $0.25 \%$ Trypsin-EDTA). $1 \mathrm{~mL}$ media was added to each well for trypsin neutralization, and this combined $1.5 \mathrm{~mL}$ mixture was added to the previous $1.0 \mathrm{~mL}$ media into the corresponding tubes. Samples were centrifuged at $300 \mathrm{~g}$ for 5 minutes, excess drug and media were removed, and pellets were resuspended with $1.5 \mathrm{~mL}$ fresh media. $0.2 \mathrm{~mL}$ of these samples were diluted in $0.8 \mathrm{~mL}$ of media, and subsequently $0.1 \mathrm{~mL}$ of these diluted samples $(2 \cdot$ $10^{5}$ cells) were plated in a 96-well plate in triplicates. After 48 hours, the XTT assay was performed for cell viability quantification. Doses of $100 \mu \mathrm{M}$ VRL and $150 \mu \mathrm{M}$ VBL were chosen for the USMB investigation aspect. 


\subsection{Cell Viability with XTT Assay}

In general, tetrazolium salts have been used as detection reagents as cell biological assays (Berridge, Herst \& Tan, 2015). XTT, (2,3-Bis-(2-Methoxy-4-nitro-5-sulfophenyl)-2Htetrazolium-5-carboxanilide, disodium salt), is a second generation tetrazolium dye used for cell proliferation, cytotoxicity and apoptosis assays (Berridge, Herst \& Tan, 2015; Scudiere et al., 1988). It measures cell proliferation based on the metabolic activity of the cells and is often used in in vitro settings (Scudiere et al., 1988). XTT is a colourless compound that becomes bright orange when reduced via the breaking apart of positively-charged quaternary tetrazole rings (Berridge, Herst \& Tan, 2015). This assay is compounded with the use of an intermediate electron acceptor, PMS (N-methyl dibenzopyrazine methyl sulfate), to greatly improve the XTT reduction into its formazan derivative. The particular XTT assay that was performed was the XTT Cell Proliferation Assay Kit (Cayman Chemical, Ann Arbor, MI, USA). The amount of product generated from this XTT reduction is directly proportional to the number of living cells in the sample (Biotum, 2017).

Ten $\mu \mathrm{L}$ of 1:1 XTT and PMS solution were added to each $0.1 \mathrm{~mL}$ well and incubated for 2 hours. Subsequently, the plate was shaken gently for 2 minutes to produce a homogeneous mixture and placed in a Spectramax® M5e Multi-Mode Microplate Reader (Molecular Devices, San Jose, CA, USA) to quantify the absorbance of the formazan at $450 \mathrm{~nm}$.

\subsection{Microbubble Agent}

FDA and Health Canada approved Definity ${ }^{\circledR}$ (Lantheus Medical Imaging, Billerica, MA, USA) MBs were used for this study. These bubbles have a mean diameter of $1.1-3.3 \mu \mathrm{m}$ and are 
comprised of octofluoropropare $\left(\mathrm{C}_{3} \mathrm{H}_{8}\right)$ gas encapsulated by a phospholipid shell. For bubble activation, a fresh vial was initially left at room temperature for approximately 30 minutes and activated using a Vial-Mix shaker (Lantheus Medical Imaging, Billerica, MA, USA) for 45 seconds. The vial was then left to equilibrate overturned for 5 minutes at room temperature. An 18 gauge needed was inserted to the end of the inverted vial to allow for venting while another 18 gauge needle and syringe were used to extract $500 \mu \mathrm{L}$ of MBs. $500 \mu \mathrm{L}$ of sterile PBS were added to the MBs to achieve $1.0 \mathrm{~mL}$ of a 1:1 ratio of MBs:PBS. The syringe was mixed by hand before treatment and mixed slightly again between every sample to maintain homogeneity. $35 \mu \mathrm{L}$ of the mixture was added to each sample, resulting in $1.7 \%$ v/v MBs to sample volume. Definity® MBs have an initial concentration of $1.2 \cdot 10^{10} \mathrm{MBs} / \mathrm{mL}$ by manufacturer's standards and for these samples, a bubble to cell ratio of $100 \mathrm{MBs} / \mathrm{cell}$ were used.

\subsection{Ultrasound Exposure}

The $1.0 \mathrm{~mL}$ samples were placed in a $0.9 \mathrm{~cm}$ diameter cylindrical closed system chamber with an acoustically transparent wall. This chamber was lowered into a deionized and degassed water tank which contained submerged transducers. The setup consisted of an L-shape arrangement with the transmitting and emitting transducers placed at each end as seen in Figure 2.1. The sample chamber placed between the two, forming a $90^{\circ}$ orientation. A $0.5 \mathrm{~cm}$ magnetic stirrer was placed in the chamber and mobilized during exposure for a homogenous mixture of cells, drug agents and MBs. The $4.2 \mathrm{~cm}$ diameter transmitting transducer used (IL0202HP, Valpey Fisher Inc., Hopkinton, MA) had a centre frequency $1.0 \mathrm{MHz}$ with a focal length of $4.0 \mathrm{~cm}$ and a beamwidth of $2.0 \mathrm{~mm}$. This emitting transducer produced the using a 100Msample/sec arbitrary waveform generator (Sony Tektronix AWG 5002C, Tektronix Japan, Ltd., Tokyo, Japan) which 
was connected to an RF amplifier (Electronics \& Innovation, Ltd., Rochester, U.S.A). The $2.5 \mathrm{~cm}$ diameter passive transducer (IL0208HP, Valpey Fisher Inc., Hopkinton, MA) had a centre frequency of $2.25 \mathrm{MHz}$ with a focal length of $8.0 \mathrm{~cm}$ and a beamwidth of $2.0 \mathrm{~mm}$. This receiving transducer was used to detect MB activity in the sample chamber during the ultrasound treatments using CompuScope MATLAB SDK (CompuScope MATLAB SDK, Lockport, IL, USA). Ultrasound exposure was initialized after the mixture was visually observed to be uniformly mixed. The chamber was placed at the focal length of the transmitting transducer and treated at $47.5,75$ or $100 \mathrm{mV}$, resulting in a corresponding acoustic peak negative pressure of 370,570 or $770 \mathrm{kPa}$ PNP at the centre of the treatment chamber. The samples were exposed to an 8 cycle 1 MHz signal with a pulse duration period (PDP) of $8 \mu$ s and a pulse repetition period (PRP) of 2 ms. The insonation time of each sample was 30 seconds. The samples were removed from the water tank after treatment and incubated in 6-well plates for 4 hours. 


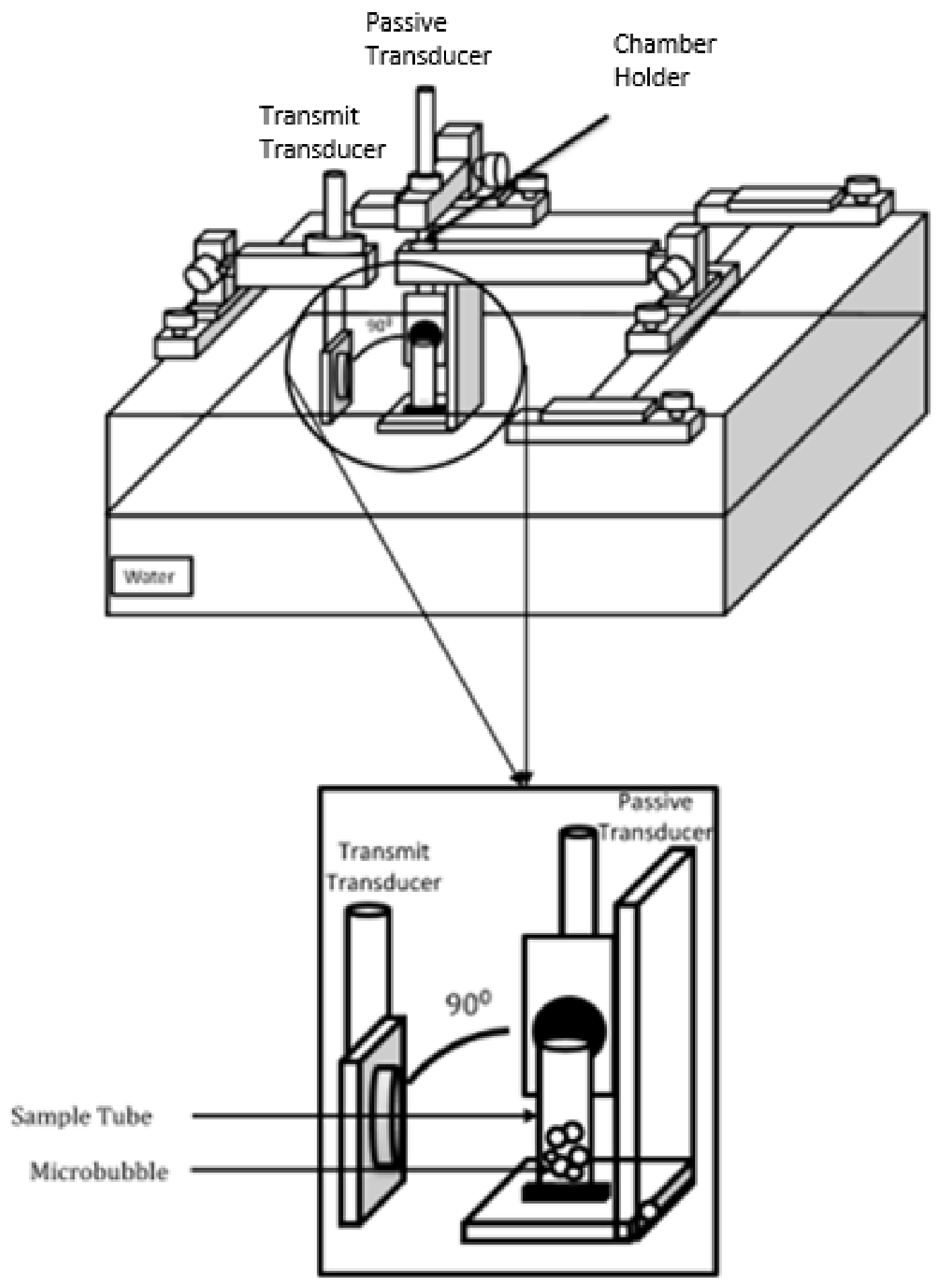

Figure 2-1 Schematic representation of treatment setup. Transmitting and passive at transducers perpendicular orientation, both facing treatment chamber. (Adapted from Shadab Momin, 2016) 


\subsection{Integrated Cavitation Dose (ICD)}

A receiving transducer was used in a Passive Cavitation Detection (PCD) system for monitoring the MB activity. Integrated Cavitation Dose (ICD) is used as a metric for quantifying MB activity irrespective of the specific US and MB parameters. During treatments, signals were acquired every $2 \mathrm{~ms}$ for an insonation time of $30 \mathrm{~s}\left(3 \cdot 10^{5} \mathrm{~ms}\right)$, resulting in 15000 time domain measurements. A Fast Fourier Transform (FFT) was applied to each signal, yielding corresponding frequency domain signals. The areas under these FFT curves for the first, second, third and fourth harmonics were generated using a $500 \mathrm{kHz}$ band centred at each harmonic. The ICD was represented as the summation of these four areas over the total $30 \mathrm{~s}$ insonation time (15 000 spectra). A background signal in the absence of USMB was subtracted from each. A Power Spectral Density (PDS) spectrum was generated for each of these frequency spectra for further qualitative analysis.

\subsection{Data Analysis}

Two-way ANOVA analysis was used to determine the statistical significance between conditions for viability analysis. Multiple comparison tests were conducted to determine P values between conditions, where $\mathrm{P}<0.05$ was established as significant. $\mathrm{R}$-squared values were calculated to assess correlations between MB activity in terms of ICD and viability. Three independent experiments were performed for each drug, with three trials per condition per experiment. Treatments were normalized to their respective untreated control condition on that experiment day and error bars represent the standard deviation of all trials. Synergism was determined using the Bliss criteria where the viability fraction of the combined treatment, $\mathrm{V}_{\mathrm{c}}$, of two independent treatments $\mathrm{V}_{\mathrm{a}}$ and $\mathrm{V}_{\mathrm{b}}$ was considered additive if it $\mathrm{V}_{\mathrm{c}} \approx \mathrm{V}_{\mathrm{a}} \cdot \mathrm{V}_{\mathrm{b}}$ and synergistic if $\mathrm{V}_{\mathrm{c}}<\mathrm{V}_{\mathrm{a}} \cdot \mathrm{V}_{\mathrm{b}}$. 


\section{3. $\quad \underline{\text { Results }}$}

The results in this study show that the combined drug + USMB treatments resulted in a lower cell viability than USMB alone or drug alone. However, the results indicate that USMB does not enhance the cytotoxic effects of vinorelbine tartrate (VRL) and vinblastine sulfate (VBL) in PC3 cancer cells; that is, no synergistic enhancement in cell death was observed with the combined treatment. The results showed that the effect was additive for USMB+VRL treatments at all PNPs. In the USMB+VBL conditions, an additive effect was observed at $370 \mathrm{kPa} P N P$, and a potentially antagonistic effect at 570 and $770 \mathrm{kPa}$ PNP. Furthermore, a linear fit regression was performed to demonstrate that cell viability correlates linearly with ICD at $370-770 \mathrm{kPa}$.

\subsection{Chemotherapy Drug Dose-Response}

The dose response of PC3 cancer cells treated for 4 hours with each chemotherapy drug -VRL (50 $-250 \mu \mathrm{M})$ and VBL $(100-250 \mu \mathrm{M})$ - are shown in Figure 3.1 and Figure 3.2, respectively, using the XTT assay. Cell viability decreased with increasing drug concentration for both drugs, as expected. Overall, a similar dose response curve was observed for both chemotherapy drugs. At lower drug concentrations (VRL: $0-70 \mu \mathrm{M}$ and VBL: $0-125 \mu \mathrm{M}$ ), cell death increased approximately up to $\sim 15 \%$. The drop-off region followed, where viability decreased at a higher rate (VRL: $70-167 \mu \mathrm{M}$ and VBL: $125-200 \mu \mathrm{M}$ ) from $\sim 85 \%$ to below $15 \%$. Finally, the plateau region occurred where viability again decreased at a lower rate, approaching 0\% (VRL: >167 $\mu \mathrm{M}$ and VBL: $200 \mu \mathrm{M}$ ). From the dose response curves, the $\sim \mathrm{IC}_{2 / 3}$ (concentration at which $\sim 2 / 3$ of cells are viable) for VRL and VBL were identified to be $100 \mu \mathrm{M}$ and $150 \mu \mathrm{M}$, respectively. These concentrations were used in the USMB combined treatment conditions. The rationale for using 
$\mathrm{IC}_{2 / 3}(\sim 2 / 3$ viable fraction) of the dose-response curve, the lower concentration of the drop-off region, is to allow drug delivery methods (such as USMB) to enhance cytotoxicity.

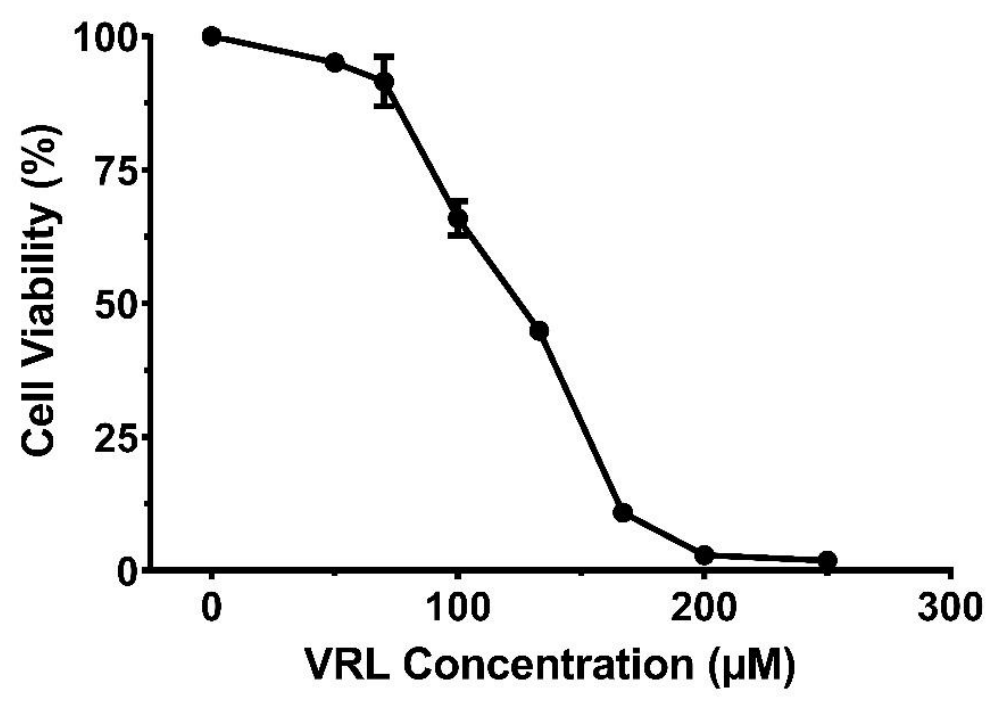

Figure 3-1 Dose-response of PC3 cells treated with increasing concentration of vinorelbine tartrate (VRL). Dose-response range tested 50-250 $\mu \mathrm{M}$. Viability determined using XTT assay. Cells were incubated for 4 hours after exposure. Normalized with respect to untreated control $n=9$ independent samples.

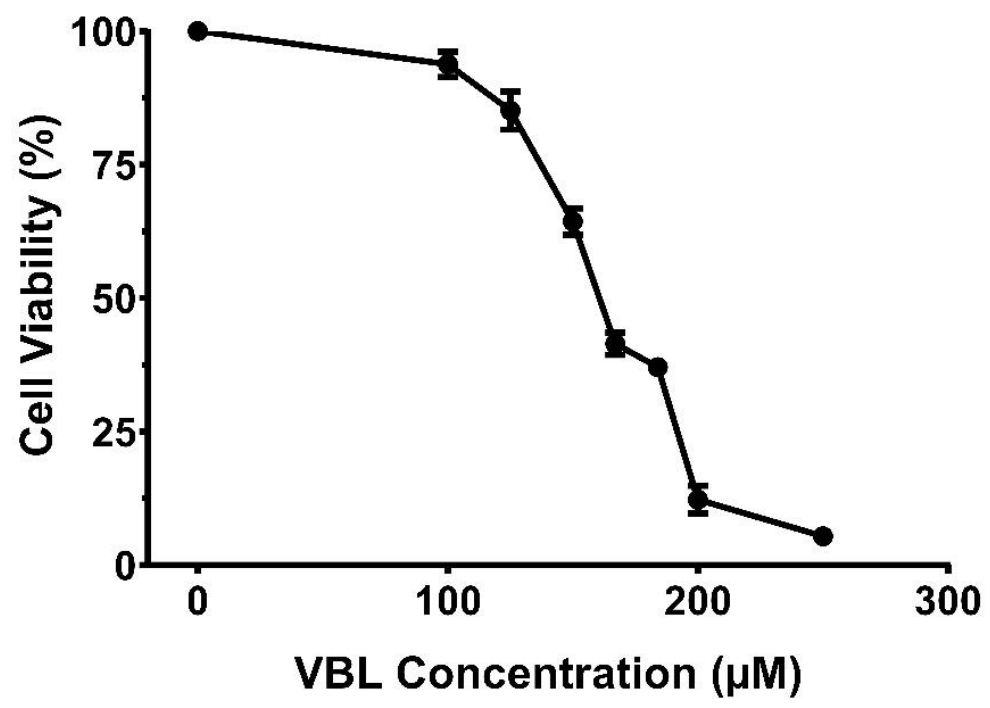

Figure 3-2 Dose-response of PC3 cells treated with increasing concentration of vinblastine sulfate (VBL). Dose-response ranged tested $100-250 \mu \mathrm{M}$. Viability determined using XTT assay. Cells were incubated for 4 hours after exposure. Normalized with respect to untreated control. $n=9$ independent samples. 


\subsection{Combined Treatment with Vinca Alkaloids and USMB}

\subsubsection{VRL and USMB}

Viability of cells treated with VRL alone $(100 \mu \mathrm{M})$, USMB alone and their combination of VRL+USMB are shown in Figure 3.3(a); the data are presented with respect to PNP $(0,370,570$ and $770 \mathrm{kPa})$. Cell viability decreased significantly with VRL alone at $100 \mu \mathrm{M}(71 \% \pm 6 \%)$ compared to untreated control, which is comparable to cell viability in VRL dose response curve $(66 \% \pm 3 \%$; Figure 3.1). Overall, cell viability decreases with increasing PNP with and without VRL. USMB alone significantly decreased cell viability at all PNPs compared to untreated control $(\mathrm{P}<0.0003)$. In these USMB alone conditions, cell viability was significantly lower at $770 \mathrm{kPa}$ PNP $(62 \% \pm 10 \%)$ compared to $370 \mathrm{kPa}(89 \% \pm 5 \%)$ and $570 \mathrm{kPa}(84 \% \pm 3 \%)(\mathrm{P}<0.0001)$. No statistically significant difference was observed in cell viability at $370 \mathrm{kPa}$ and $570 \mathrm{kPa} \mathrm{PNP}$ USMB alone conditions $(\mathrm{P}=0.6765)$. In the combined VRL+USMB condition, USMB significantly decreased cell viability compared to VRL alone at 570 and $770 \mathrm{kPa} P N P(\mathrm{P}<0.0001)$. Furthermore, a significant difference in cell viability was observed when PNP increased from 570 $\mathrm{kPa}$ to $770 \mathrm{kPa}$ PNP in the combined VRL+USMB condition $(\mathrm{P}=0.0357)$.

Cell viability of the combined treatment of VRL+USMB is significantly lower compared to USMB alone at all PNPs $(\mathrm{P}<0.0003)$ (Figure 3.3a). In addition, the effect of the combined treatment of VRL and USMB on cell viability is additive; Figure 3.3b shows the cell viability ratio of USMB alone and VRL+USMB normalized to their perspective $0 \mathrm{kPa}$ PNP condition. No statistically significant difference was observed in cell viability ratio at each PNP. 

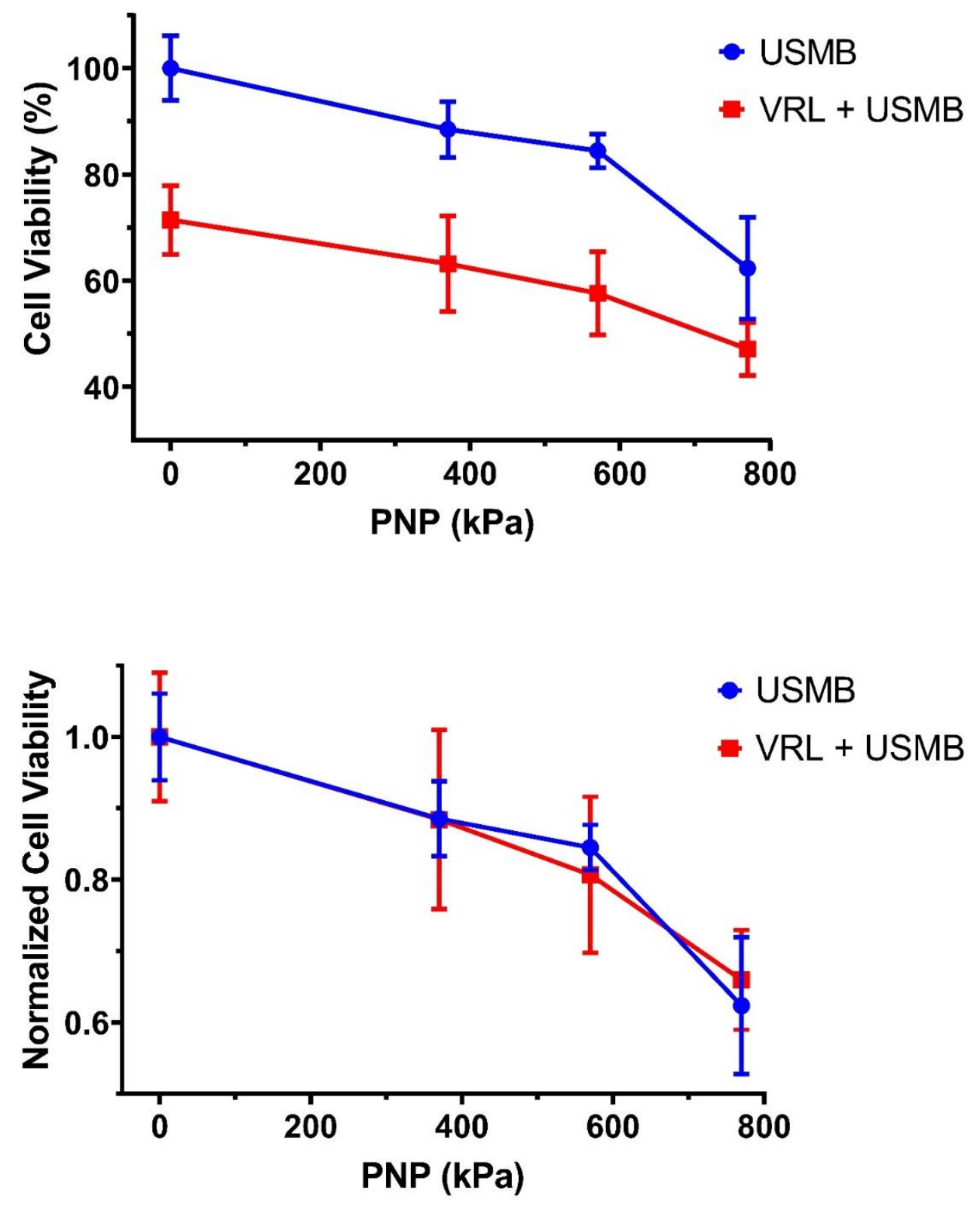

Figure 3-3 Cell viability of combination treatment of PC3 cells treated with USMB in the presence and absence of $100 \mu \mathrm{M}$ vinorelbine tartrate (VRL). Cells were incubated for 4 hours after treatment. Viability determined using XTT assay. (a) All conditions normalized with respect to untreated control. (b) USMB conditions normalized with respect to untreated control, $U S M B-V R L$ conditions normalized with respect to VRL alone. USMB treatment exposure conditions: $1.0 \mathrm{MHz}, P D P=8 \mathrm{cycles}$, $P R P=2 \mathrm{~ms}$, exposure time $=30 \mathrm{~s}, P N P=370,570,770 \mathrm{kPa} . \mathrm{n}=9$ independent samples. 


\subsubsection{VBL and USMB}

Figure 3.4(a) shows the viability of cells treated with VBL alone, USMB alone and the combination of VBL+USMB. The data is presented with respect to PNP $(0,370,570$ and 770 $\mathrm{kPa}$ ). The overall trend shows a decrease in cell viability with increasing PNP with and without VBL. USMB alone significantly decreases cell viability at all PNPs in comparison to untreated control. A significant difference in cell viability was observed between all three PNP USMB conditions: At $370 \mathrm{kPa}(91 \% \pm 3 \%), 570 \mathrm{kPa}(83 \% \pm 5 \%)$ and $770 \mathrm{kPa} \mathrm{PNP}(66 \% \pm 3 \%)$, where the largest decrease in cell death was observed between 570 and $770 \mathrm{kPa} P N P(\mathrm{P}<0.0001)$. Cell viability decreased significantly with $\mathrm{VBL}$ alone at $150 \mu \mathrm{M}(67 \% \pm 1 \%)$ compared to untreated control, as expected ( $64 \pm 2.5 \%$; Figure 3.2). In the VBL+USMB treatment condition, a significant difference was observed between VBL alone $(67 \% \pm 1 \%)$ compared to VBL+USMB at $570 \mathrm{kPa}$ $(62 \% \pm 2 \%)$ and VBL+USMB at $770 \mathrm{kPa} \mathrm{PNP}(49 \% \pm 2 \%)$, corresponding to decrease of $\sim 5 \%$ and $\sim 18 \%$, respectively. Cell viability with VBL+USMB at $770 \mathrm{kPa}$ PNP is significantly lower compared to VBL+USMB at $570 \mathrm{kPa}(\mathrm{P}<0.0001)$. This is consistent with the decrease in cell viability using USMB alone which occurred at the same PNP interval.

Figure 3.4a further shows that cell viability of the combined treatment of VBL+USMB is significantly lower in comparison to USMB alone at all PNPs $(\mathrm{P}<0.0001)$. Figure 3.4(b) shows the cell viability ratio of USMB alone and VBL+USMB normalized with their perspective $0 \mathrm{kPa}$ PNP condition. No statistically significant different is observed between USMB alone and VBL+USMB at $370 \mathrm{kPa} P N P$, indicating an additive effect $(\mathrm{P}=0.5024)$. However, the cell viability ratio of VBL+USMB at the 570 and $770 \mathrm{kPa}$ PNPs is significantly higher than USMB alone $(\mathrm{P}<0.0001)$, suggesting the presence of antagonistic effect with VBL. 

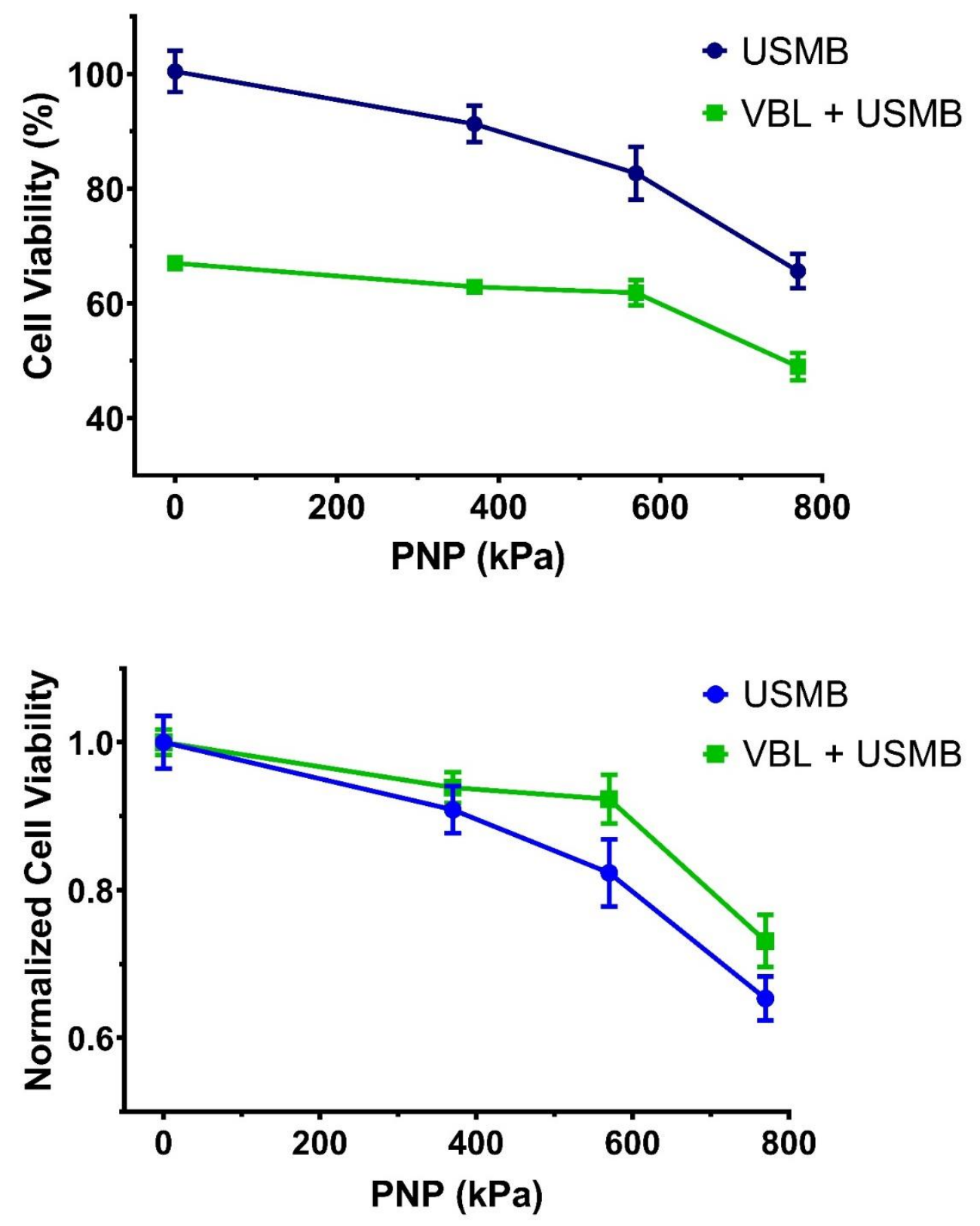

Figure 3-4 Cell viability of combination USMB treatment of PC3 cells treated in the presence and absence of $150 \mu M$ vinblastine sulfate (VBL). Viability determined using XTT assay. (a) Conditions normalized with respect to untreated control. (b) USMB alone conditions normalized with respect to untreated control, VBL+USMB conditions normalized with respect to VBL alone. USMB treatment exposure conditions: Acoustic frequency $=1.0 \mathrm{MHz}, P D P=8 \mathrm{cycles}, P R P=2 \mathrm{~ms}$, exposure time $=30 \mathrm{~s}, P N P=370,570$, $770 \mathrm{kPa} . \mathrm{n}=9$ independent samples. 


\subsection{Vinca Alkaloids with USMB}

In both VRL+USMB and VBL+USMB treatments, viability was significantly lower at 570 $\mathrm{kPa}$ and $770 \mathrm{kPa} \mathrm{PNP}$ in comparison to drug alone. This effect was additive in VRL+USMB conditions for all pressures, based on the Bliss criteria. Whereas, for VBL+USMB treatments, an additive effect was observed at $370 \mathrm{kPa}$ PNP, and an antagonistic effect was seen at 570 and 770 $\mathrm{kPa}$ PNP. No synergistic effect on cell viability with combining USMB to vinca alkaloids class drugs was observed within the experimental conditions of this study.

The lowest cell viability of $47 \% \pm 5 \%$ with VRL+USMB was achieved at the highest PNP of $770 \mathrm{kPa}$ used in this study. This is comparable to a cell viability with VRL alone at $130 \mu \mathrm{M}$. This indicates that USMB has increased the effective dose response of VRL by approximately $30 \%$ (as interpolated using Figure 3.1). The lowest cell viability of $49 \% \pm 2 \%$ with the VBL+USMB was achieved at $770 \mathrm{kPa}$ PNP, corresponding to viability achieved with VBL alone at $160 \mu \mathrm{M}$ using interpolation in Figure 3.2. USMB enhanced the effective dose response of VBL by approximately $7 \%$.

\subsection{MB Acoustic Response}

To determine the relationship of the MB acoustic response with the cellular viability, the acoustical signals from microbubbles were recorded using a Passive Cavitation Detection (PCD) system and quantified using Integrated Cavitation Dose (ICD). Figure 3.5 shows the ICD with increasing PNP at $0,370 \mathrm{kPa}, 570 \mathrm{kPa}$ and $770 \mathrm{kPa}$, and Figure 3.6 shows the Power Density Spectrum (PDS) generated from the frequency spectra of the emissions at $370 \mathrm{kPa}$ (Figure 3.6 a), $570 \mathrm{kPa}$ (Figure $3.6 \mathrm{~b}$ ) and $770 \mathrm{kPa}$ (Figure 3.6 c) PNP. As seen in Figure 3.5, an increase in ICD correlated positively with an increase in PNP. A larger increase in ICD is observed from 570 
- $770 \mathrm{kPa} \mathrm{PNP}$ in comparison to $370 \mathrm{kPa}-570 \mathrm{kPa}$, suggesting higher MB activity at the higher acoustic pressure. This increased value can be attributed to non-linear MB response or inertial cavitation behaviour. As shown in Figure 3.6, the amplitude measured, at the fundamental (1.0 $\mathrm{MHz})$, and notably the second (2.0 MHz), third (3.0 MHz) and to a lesser extent fourth (4.0 MHz) harmonic peaks increase with increasing PNP. This increase is attributed to the increased MB response, particularly the escalation of non-linear oscillations. The harmonic emissions in the 370 and $570 \mathrm{kPa}$ PNP spectra are seen to have relatively sharp peaks, whereas those in the $770 \mathrm{kPa}$ spectrum can be observed to have a wider band at the second, third and fourth harmonics. These can be attributed to the broadband emissions, where increased $\mathrm{MB}$ oscillations generate higher response amplitude, leading to smaller gaps between the harmonics.

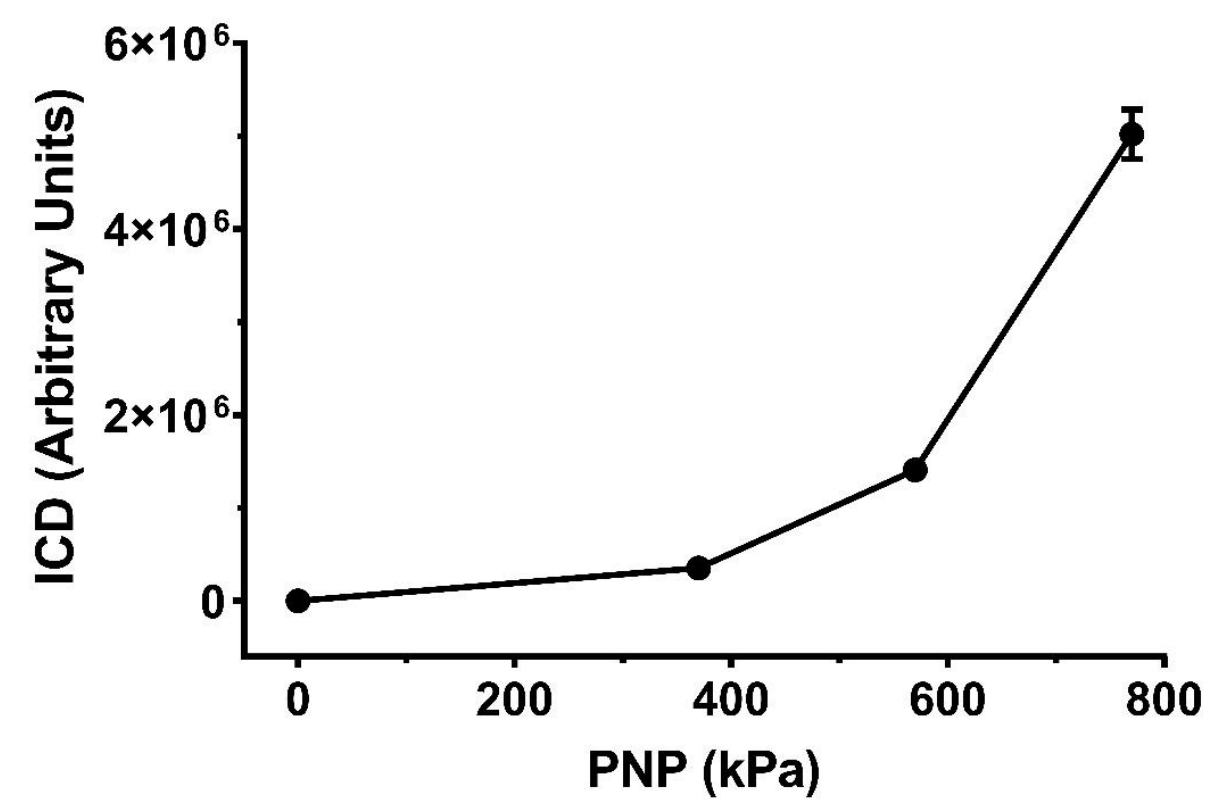

Figure 3-5 ICD of MB acoustics as a function of increasing PNP. Acoustic frequency $=1.0 \mathrm{MHz}, P D P=8 \mathrm{cycles}, P R P=2 \mathrm{~ms}$, exposure time $=30$ s. $n=9$ independent samples. 

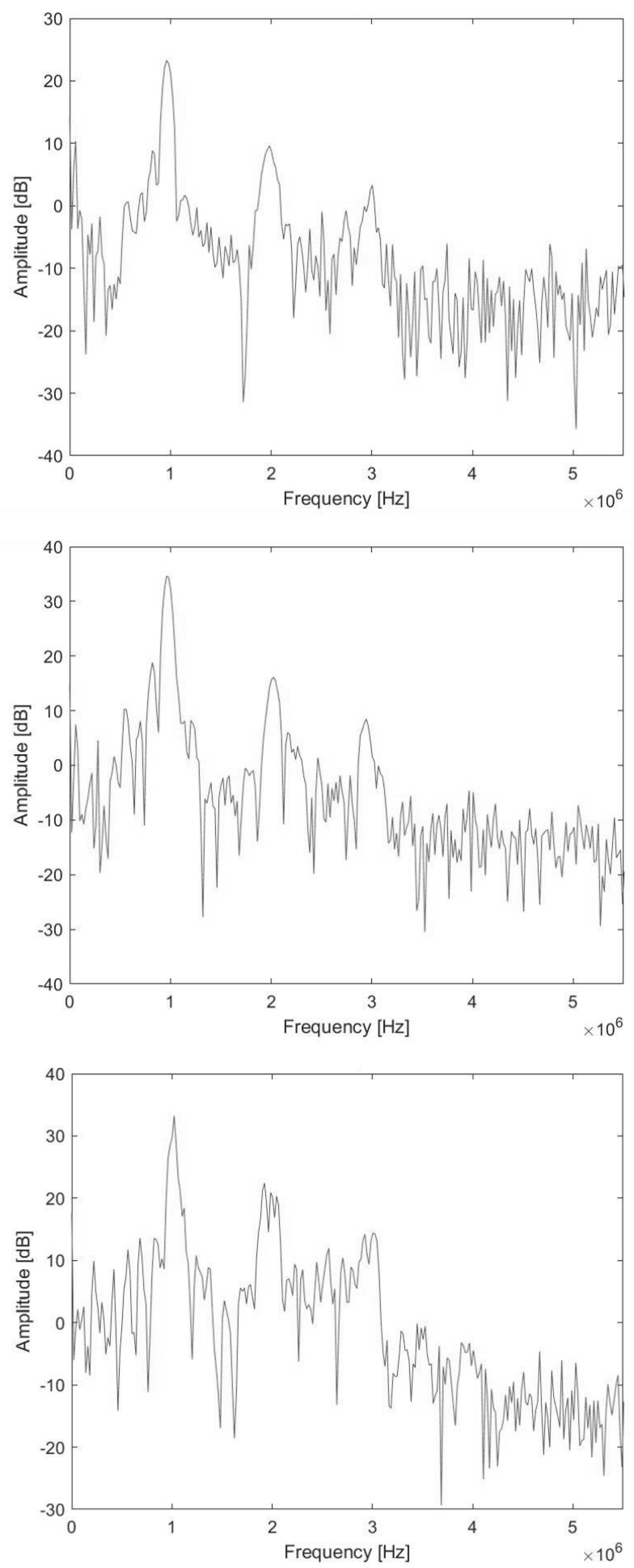

Figure 3-6 Spectral energies generated by Definity ${ }^{\circledR} \mathrm{MBs}$ at (a) $370 \mathrm{kPa} P N P$ (b) $570 \mathrm{kPa} P N P$ (c) $770 \mathrm{kPa} P N P$. 


\subsection{Cell Viability and MB Acoustic Response}

To determine the relationship between cell viability and MB activity, the ICD rather than PNP is used. ICD is considered a more accurate representation of MB activity as it is based on its measured acoustic response. Figure 3.7 shows the cell viability of USMB with and without the vinca alkaloid drugs with respect to ICD; VRL and VBL in shown in Figure 3.7a and Figure 3.7b, respectively. Cell viability decreases with ICD when treated with either USMB or drug + USMB. The trends suggest that a decrease in viability is proportional to an increase in ICD.

To determine whether the relationship between cell viability and ICD is linear, a linear fit regression analysis is performed within the $370-770 \mathrm{kPa}$ PNP treatment range. Figure 3.8 shows the linear fit of cell viability and ICD for VRL (Figure 3.8a) and VBL (Figure 3.8b). An $\mathrm{R}^{2}$ value of 0.9941 and 0.9842 is observed for USMB and VRL+USMB, and 0.9869 and 0.9769 is shown for USMB and VBL+USMB, respectively. Within the range of 370-770 $\mathrm{kPa}$ with USMB alone and with drug + USMB, the relationship is linear. 

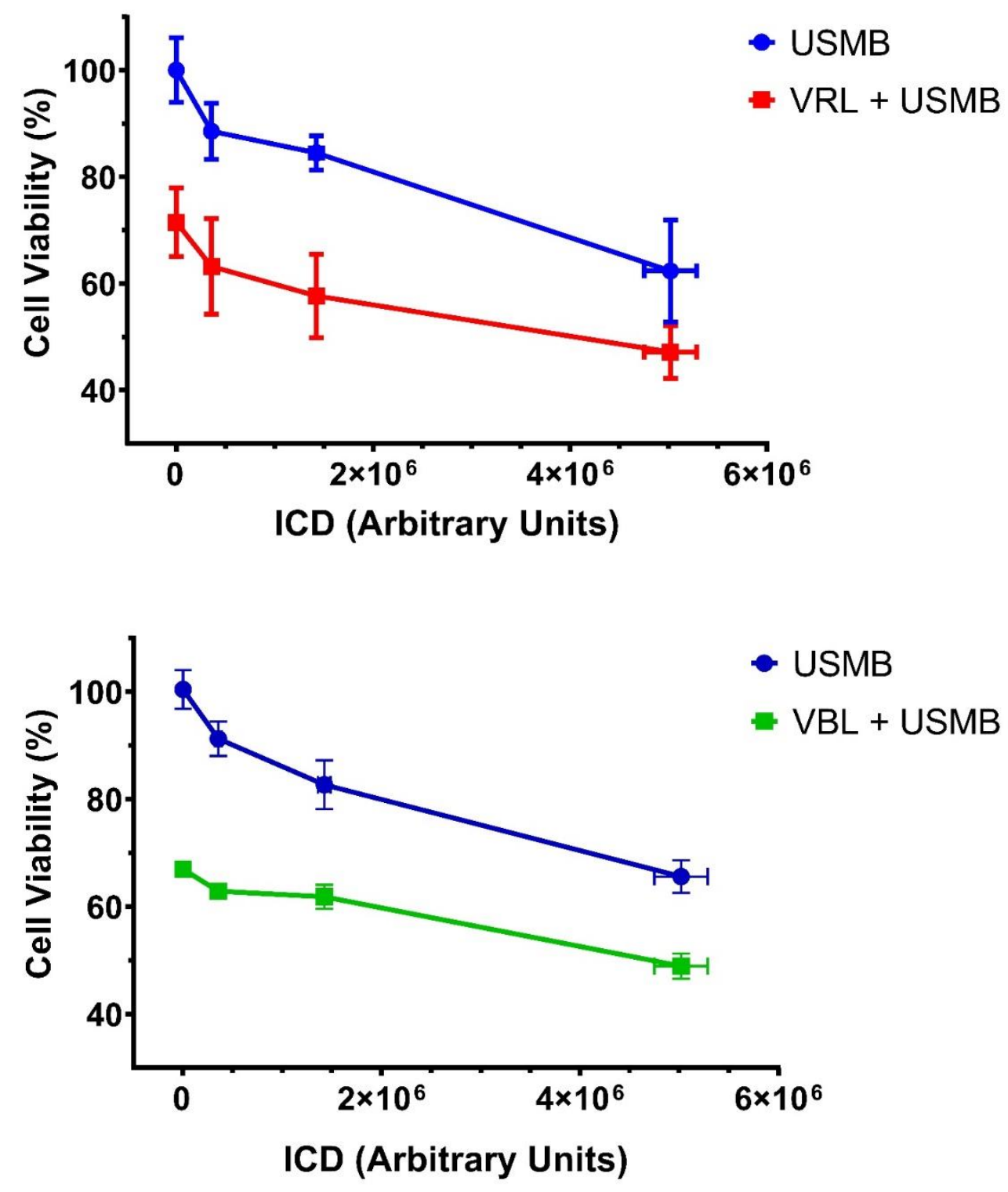

Figure 3-7 Cell viability with respect to ICD for (a) VRL (b) VBL. All values normalized to untreated control. Acoustic frequency $=1.0$ $M H z, P D P=8$ cycles, $P R P=2 \mathrm{~ms}$, exposure time $=30 \mathrm{~s}, P N P=370,570,770 \mathrm{kPa} . n=9$ independent samples. 

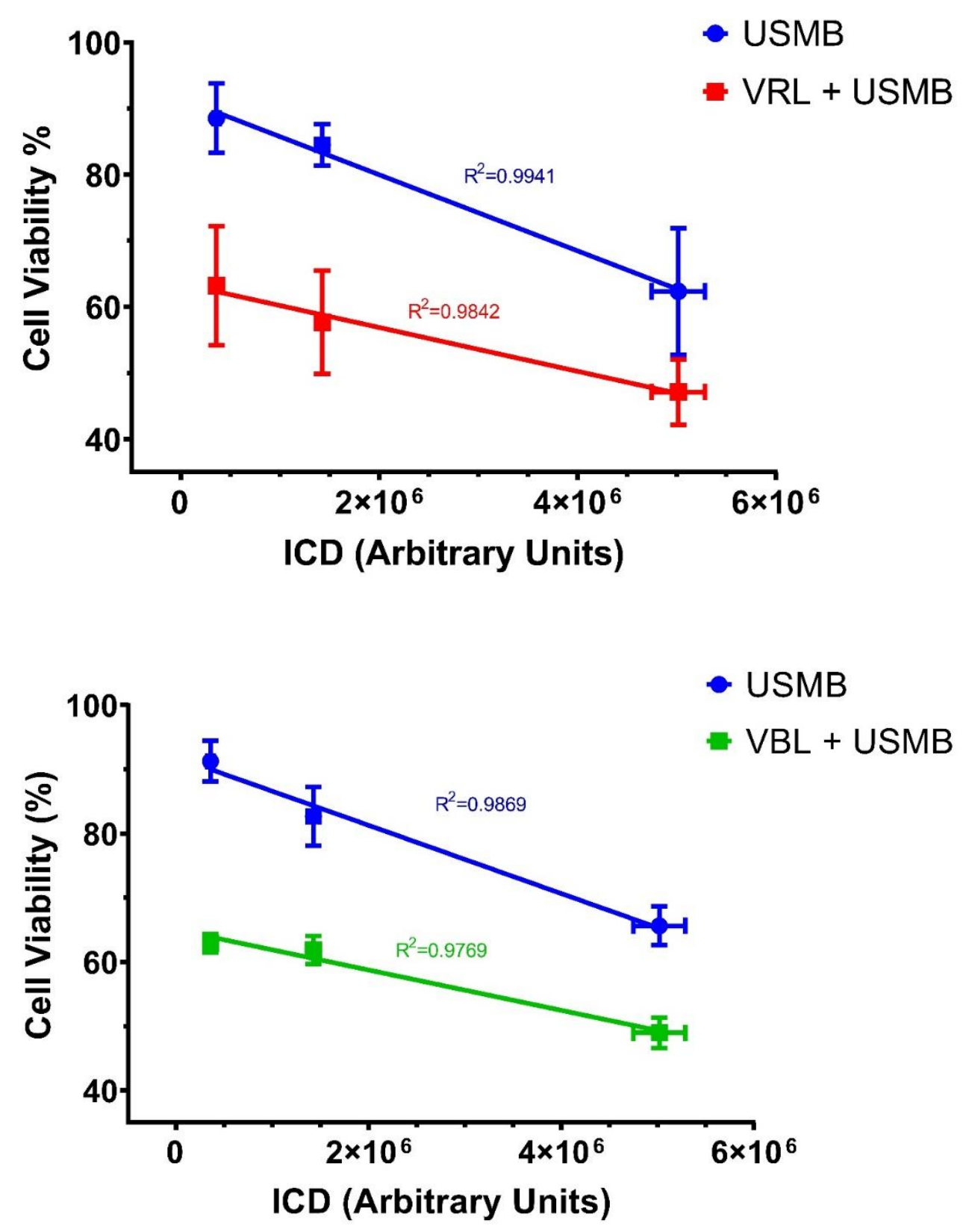

Figure 3-8 Cell viability with respect to ICD. Trendline shown for USMB alone and drug + USMB at $370-770 \mathrm{kPa} P N P$ range for (a) $V R L$ (b) VBL. Acoustic frequency $=1.0 \mathrm{MHz}, P D P=8$ cycles, $P R P=2 \mathrm{~ms}$, exposure time $=30 \mathrm{~s}, P N P=370,570,770 \mathrm{kPa} . n=9$ independent samples. 


\section{Discussion}

This study demonstrated that the cytotoxicity of vinca alkaloids chemotherapy drugs was not enhanced by USMB under the exposure conditions of this study; although the cell viability with the combined treatment was similar or lower compared to drug alone. The combined treatment of USMB with vinorelbine tartrate (VRL) was additive, however, vinblastine sulfate (VLB) with USMB exhibited antagonistic effects specifically at higher pressures. To correlate these findings to MB activity, a linear regression analysis showed a linear fit between ICD and cell viability ranging from $370-770 \mathrm{kPa} \mathrm{PNP}$.

The combination of neither VRL nor VBL with USMB were found to have an enhanced cytotoxic effect. In this study, enhanced cytotoxicity was described as the ability of an additional therapy, USMB, to synergistically decrease cell viability of a drug treatment below the level that each treatment would induce alone. This synergistic effect has been shown to be important in chemotherapy and USMB combined treatments as it affirms that the improvement allows the drug to overcome an otherwise difficult barrier to achieve cytotoxicity. USMB has been previously shown to both enhance the uptake and cytotoxic effects of chemotherapy drugs (Lentacker et al., 2010; Escoffre, Piron, Novell, \& Bouakaz, 2011; Deng et. al., 2014), For example Yang et al. demonstrated that doxorubicin in combination with USMB synergistically enhanced cell death and increased apoptotic and necrotic induction in K562 cells (Yang, Wang, Wang, Su, \& Liu, 2014). Due to the fluorescent nature of doxorubicin, they were also able to show that USMB induced a 3.9 fold intracellular increase of the drug in comparison to free drug alone. As mentioned, no vinca alkaloids have been tested in such combination treatments. Taxanes, a class of chemotherapy drugs that target the microtubules at a different binding site than vinca alkaloids (Weaver, 2014), have been used in USMB combination studies both in vitro and in vivo (Sorace, Warram, Umphrey, \& 
Hoyt, 2012; Goertz et al., 2012, Kang et al., 2010). An enhanced cytotoxic response is often reported in these studies where cell death and drug accumulations is synergistically increased. For example, Goertz et al. demonstrated that USMB treatment with docetaxel at $1 \mathrm{MHz}$ frequency and 1.65 MPa PNP induced an acute reduction in tumour perfusion and a synergistic enhancement in necrosis and apoptosis in a mouse model implanted with PC3 tumours (Goertz et al., 2012).

The disparity of the outcomes observed in our vinca alkaloid combined treatments in comparison to the taxanes may be in part be associated with the mechanism of drug uptake. In terms of uptake pathways, docetaxel and paclitaxel of the taxane class rely on the OATP1B3 (SLCO1B3) and OAT2 transporters for cellular entry, respectively (Oshiro et al., 2010). These energy-dependent transporters are recognized as the class's most efficient influx regulators. Conversely, vinca alkaloids do not require such pathways and instead enter the cells via passive diffusion. This means that cells may readily take up extracellular vinca alkaloids without the burden of an arduous entrance pathway. In fact, it has been shown in human promyelocytic leukemia HL-60/Cl cells that rates of vinca alkaloid uptake remained unaffected by the depletion of cellular adenosine triphosphate (ATP), further supporting that intracellular accumulation is not an energy-dependent process (Ferguson \& Cass, 1985). This difference suggests that one of the reasons why taxanes may benefit synergistically from USMB treatments is the acquired ability to bypass limiting transporter-dependent uptake and passively enter the cell. The pore formation (De Cock et al., 2015), enhanced endocytosis (Meijering et a., 2009) and fluid-phase uptake (Fekri, Delos Santos, Karshafian, \& Antonescu, 2016) effects generated by USMB can potentially be advantageous for these taxanes by allowing direct intracellular access. Vinca alkaloids may not require this alternative path of entry as they do not share the same biophysical hurdle. It can be postulated that because of their passive nature, the addition of USMB does not increase 
intracellular vinca alkaloid accumulation, and thus cytotoxic effects. The study suggests that the mechanism of uptake appears to be an important factor in USMB potentiated chemotherapy.

The effect of USMB on the cytotoxicity of the two vinca alkaloid drugs was different. The VRL and USMB treatments had an additive effect on cell viability at all three PNPs. For VBL combined with USMB, the effect was found to be additive at $370 \mathrm{kPa}$ PNP, and antagonistic at 570 and $770 \mathrm{kPa}$ PNP. In a combined study of vinca alkaloid drugs and ionizing radiation, the radiosensitizaiton effects of the two vinca alkaloids, vinflunine and vinorelbine were not similar; vinflunine resulted in a more favourable outcome due to its toxicity profile (Simoens et al., 2008). This is in agreement with the variability in vinca alkaloid drugs with other treatments, such as USMB in this study. Further studies with vinca alkaloids will give a better insight into the pattern of USMB response with this class.

The combined treatment of USMB with either VRL or VBL showed a lower cell viability at $570 \mathrm{kPa}$ and lower still at $770 \mathrm{kPa}$ PNP, compared to drug alone. Since it was shown that USMB did not enhance the cytotoxicity of either drug, the additional cell death in drug + USMB treatments can be attributed to the USMB effects. This is in accordance with literature that demonstrates that at higher pressures, shock waves and fluid microjets can form in the environment of the MBs, and a high mechanical stress can be induced in nearby cells (Fan, Kumon, \& Deng, 2014). This damage has been shown to induce various kinds of cell wounding that can lead to necrosis (Schlicher, Hutcheson, Radhakrishna, Apkarian, \& Prausnitz, 2010). Apoptotic pathways can be triggered as well, which can be attributed to free radical generation, reactive oxygen species and influx of $\mathrm{Ca}^{2+}$ (Honda, Kondo, Zhao, Lorento, \& Kitigawa, 2004). Additionally, as seen mostly in the higher pressure settings, the mechanical stress can prompt the formation of cell membrane 
pores which cannot reseal, leading to apoptotic pathways (Lentacker, De Cock, Deckers, De Smedt, \& Moonen, 2014).

In an attempt to correlate $\mathrm{MB}$ activity to cell viability, a linear regression was performed at the $370-770 \mathrm{kPa}$ PNP range and demonstrated a linear fit correlating an increase in ICD to a decrease in viability for both VRL+USMB and VBL+USMB. These findings suggest that MB response in terms of ICD can serve as a direct indicator of cell viability at both non-inertial and inertial cavitation regions. These regions were confirmed by previous studies with the setup used in this experiment that showed a sharp increase in ICD at $640 \mathrm{kPa}$ PNP onwards (Momin, 2016). This increase is attributed to a transition from MBs oscillating in the non-inertial to inertial cavitation regime. Furthermore, higher broadband emissions were observed at the higher PNP, which is in accordance with increased harmonic amplitudes in the inertial cavitation (King et al., 2010). Experiments must be conducted at both lower and higher ICD regions to further verify the linearity of this relationship. 


\section{Conclusion}

In conclusion, this study showed that USMB does not enhance the cytotoxic effects of the vinca alkaloid agents such as vinorelbine tartrate (VRL) and vinblastine sulfate (VBL). At all combined treatment conditions, cell viability was similar or lower than drug alone. VRL in combination with USMB showed an additive effect at all PNPs, whereas VBL with USMB treatment resulted in an additive effect at a low pressure, and antagonistic at higher PNPs. The correlation between increasing ICD and decreasing cell viability was found to be linear for both VRL and VBL treatments with USMB. This work suggests that the mechanism of uptake of a drug is an important factor in USMB potentiated chemotherapy.

\section{6. $\quad$ Future Work \\ 6.1 HPLC VRL Accumulation Analysis}

The next goal of this study is to measure the intracellular drug content and determine the effects of USMB treatment on the accumulation of the chemotherapy agent. This was attempted with unsatisfactory results using a High Performance Liquid Chromatography (HPLC) method for VRL. HPLC is a type of column chromatography used to separate and identify chemical compounds within a sample (Sirard, 2012). After a chemical separation, a spectrophotometer is used to detect the light absorption of the compounds at desired wavelengths. The method was constructed and altered from work by Debal et. al, for optimal VRL measurement (Debal, Morjani, Millot, \& Angiboust, 1992).

Cells were incubated with increasing concentration of VRL $1.5 \cdot 10^{6}$ cells in $1.0 \mathrm{~mL}$ suspension. The samples were then incubated for 4 hours, as were done for the viability samples. 
Following the exposure, the cells were removed and centrifuged at $300 \mathrm{~g}$ for 10 minutes. The supernatant was removed and passed through a $0.22 \mu \mathrm{m}$ PTFE filter to prevent precipitation in the HPLC system. These samples were then taken for HPLC analysis. The leftover pellet was resuspended in a $0.2 \mathrm{~mL} 10 \% \mathrm{SDS}$ detergent for 30 minutes as intended for cell lysis. After cell degradation, this solution was then centrifuged at $3000 \mathrm{~g}$ for 10 minutes. The supernatant of these samples were then taken for HPLC analysis.

The HPLC analysis was performed on an Agilent (Agilent Technologies, Santa Clara, CA, USA) 1200 series machine at the Ryerson University Analytical Centre (RUAC). An Agilent C18 Reversed-Phase HPLC column $(250 \mathrm{~mm} \times 4.6 \mathrm{~mm}, 5 \mathrm{um})$ at $25^{\circ} \mathrm{C}$ was used for detecting the chemotherapy drug samples. A flow rate of $2.0 \mathrm{~mL} \cdot \mathrm{min}^{-1}$ was used with an injection volume of 20 $\mu \mathrm{L}$. A combination of HPLC-grade methanol, acetonitrile and phosphate buffer was used for the mobile phase. A gradient elution profile method was set with varying ratios of the solvents, as seen in Table 4.1. The $50 \mathrm{mM}$ Sodium Phosphate Dibasic Anhydrous $\left(\mathrm{Na}_{2} \mathrm{HPO}_{4}\right)$ buffer was acidified to $\mathrm{pH} 4.0$ using o-phosphoric acid $\left(\mathrm{H}_{3} \mathrm{PO}_{4}\right)$.

Table 4.1: Gradient elution profile for VRL detection

\begin{tabular}{|l|l|l|l|}
\hline \multirow{2}{*}{ Time (min) } & \multicolumn{3}{|l|}{ Mobile Phase (Solvents) } \\
\cline { 2 - 4 } & Methanol (\%) & Acetonitrile (\%) & $\begin{array}{l}\text { Phosphate Buffer } \\
\left(\mathrm{Na}_{2} \mathrm{HPO}_{4}\right)(\%)\end{array}$ \\
\hline $0-5$ & 25 & 35 & 40 \\
\hline $5-10$ & 35 & 30 & 35 \\
\hline $10-15$ & 30 & 35 & 35 \\
\hline 15 & 30 & 35 & 35 \\
\hline
\end{tabular}


UV absorption of the VRL was used to create calibration curves where VRL was diluted in both $10 \%$ SDS and RPMI media (10\% FBS, $1 \% \mathrm{P} / \mathrm{S})$ to account for both cell pellet and supernatant drug accumulation. Absorption was detected at 215, 254 and $268 \mathrm{~nm}$ wavelengths and $215 \mathrm{~nm}$ was was found to have the highest peak absorbance. An example of the VRL measurement in $10 \%$ SDS is shown in Figure 4.1, where the drug is detected between 6-8 minutes as a measure of the intensity of absorbance in milli-Absorbance units (mAU).

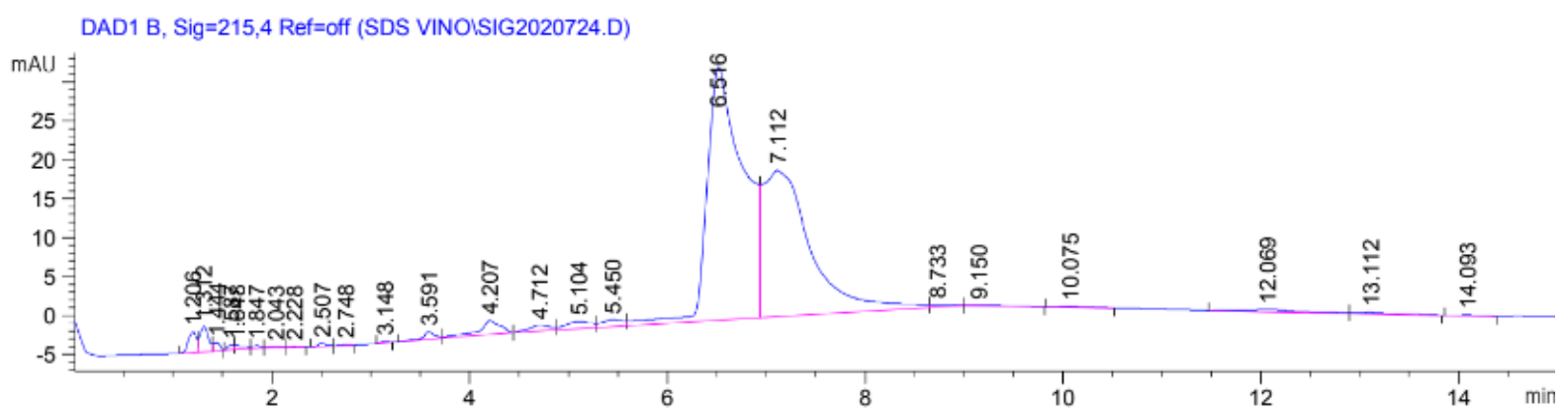

Figure 6-1 VRL spectrogram. Detected at $215 \mathrm{~nm}$. Obtained using a gradient elution profile from HPLC measurement. Measured in milli-Absorbance units.

Following absorption detection, the elution peaks were integrated for the area under the curve, which were directly proportional to the intracellular concentration (cell pellet) and extracellular environment concentration (supernatant). The calibration curve for VRL/10\% SDS and VRL/RPMI media is show in Figure 6.2 and Figure 6.3, respectively. A $3.6-462 \mu \mathrm{M}$ VRL concentration range is shown, translating to $0.004-0.498 \mathrm{mg} / \mathrm{mL}$. 


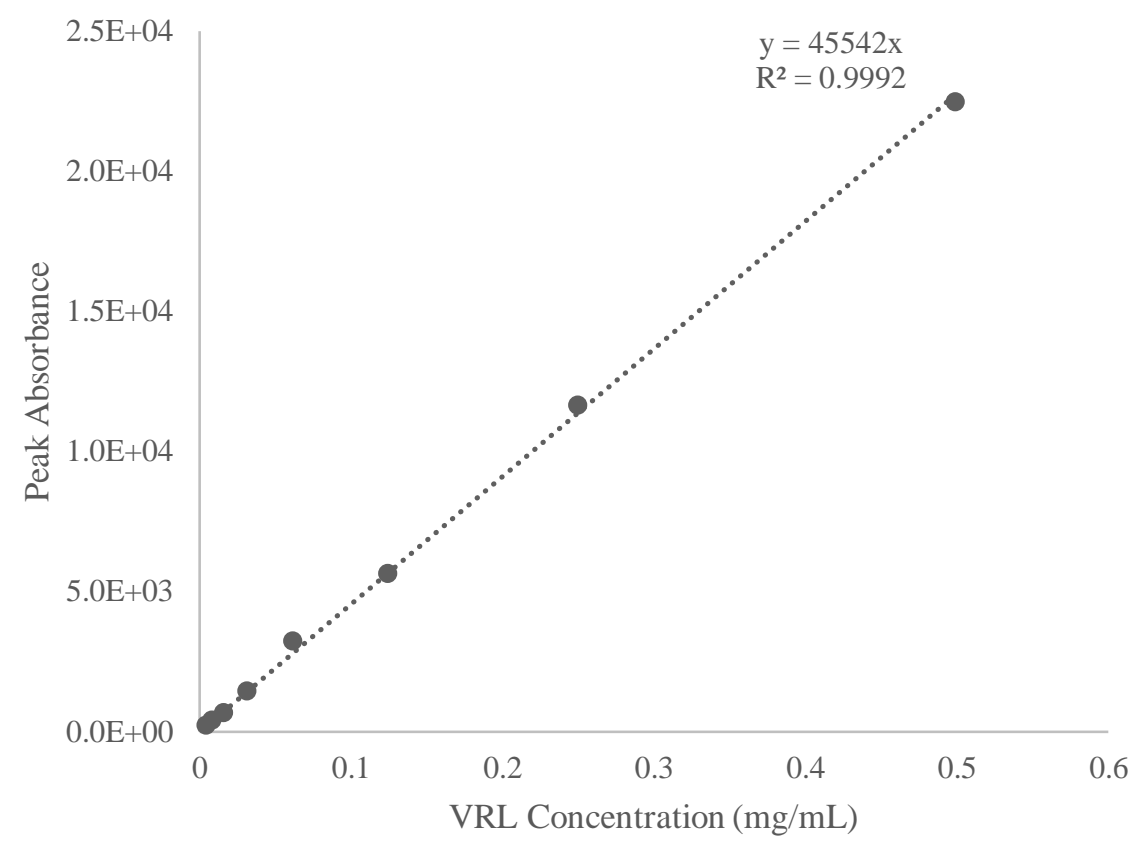

Figure 6-2 Calibration curve for increasing concentrations of VRL in 10\% SDS. Detected at $215 \mathrm{~nm}$ from HPLC measurement. Measured in Peak Absorbance

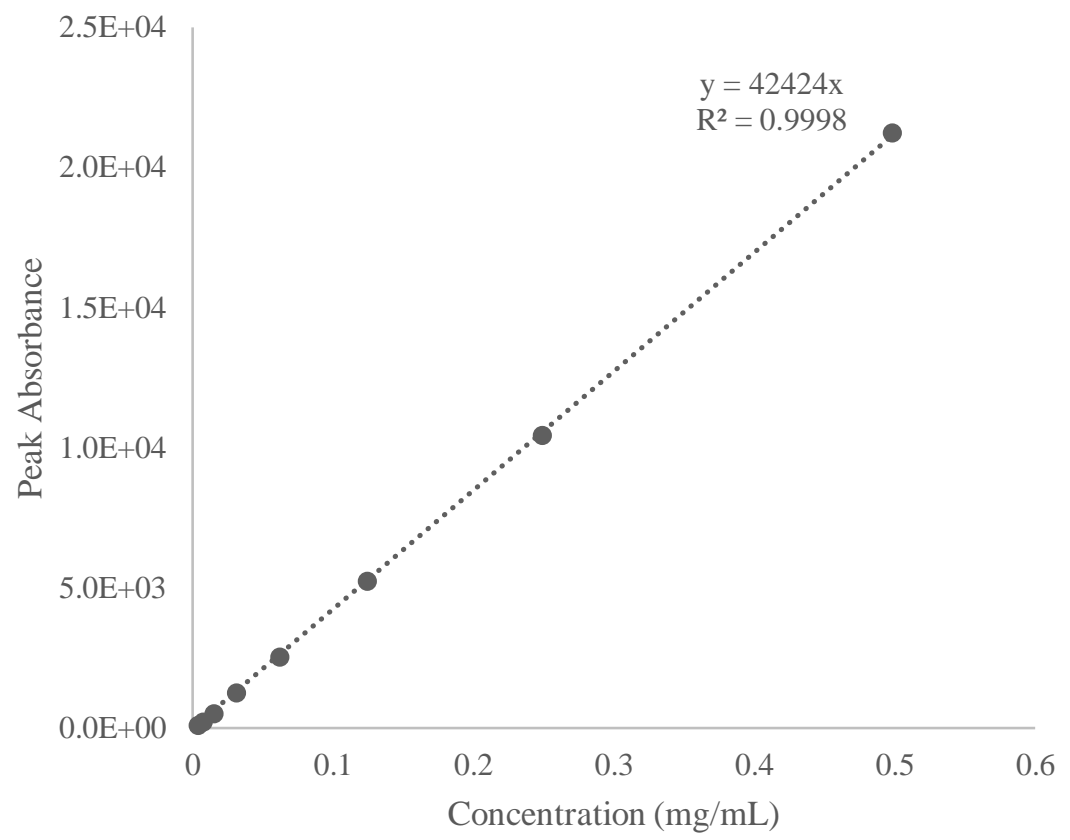

Figure 6-3 Calibration curve for increasing concentrations of VRL in RPMI media. Detected at $215 \mathrm{~nm}$ from HPLC measurement. Measured in Peak Absorbance. 
Measurements were then taken to determine the supernatant and intracellular VRL concentration after a 4 hour incubation as seen in Figure 6.4. The data is shown in terms of the mass of VRL in the supernatant as well as the lysed pellet. The VRL mass of the supernatant increases with increasing exposed concentration as expected. The VRL mass of the pellet however does not increase with increasing exposed concentration. This could very well suggest that increasing the exposure concentration does not affect the intracellular concentration even though more cell death is occurring. However, because no intracellular change is seen at all, this cannot be claimed.

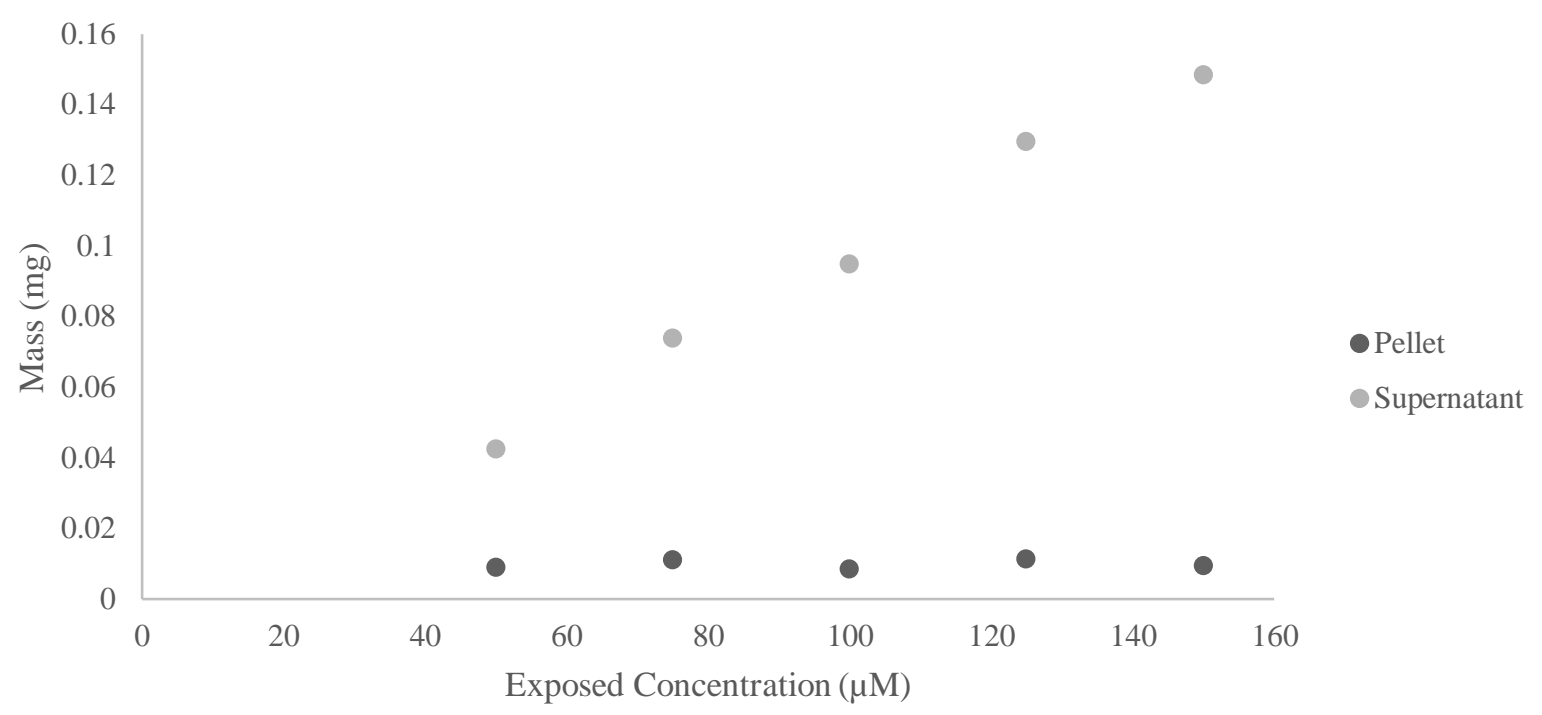

Figure 6-4 Intracellular (pellet) and supernatant VRL mass as a function of increasing exposed VRL concentration.

Finally, an experiment was done to test if USMB can affect the intracellular VRL concentration as shown in Figure 6.5. Cells were exposed to $100 \mu \mathrm{M}$ VRL and treated at $770 \mathrm{kPa}$ at the same exposure conditions as throughout this study. The samples were then incubated for varying lengths post-USMB treatment: $5 \mathrm{~min}, 30 \mathrm{~min}, 1 \mathrm{hr}, 2 \mathrm{hr}, 3 \mathrm{hr}$, and $4 \mathrm{hr}$. Similar to the outcome of data from Figure 4.4 above, no change was seen for the intracellular (pellet) mass for 
both in the presence and absence of USMB. No difference was seen in the mass at increasing incubation time as well. As mentioned, it could very well be that this observed phenomenon is in fact the true result of the treatment, however since there is no basis to this claim, it cannot be confirmed.

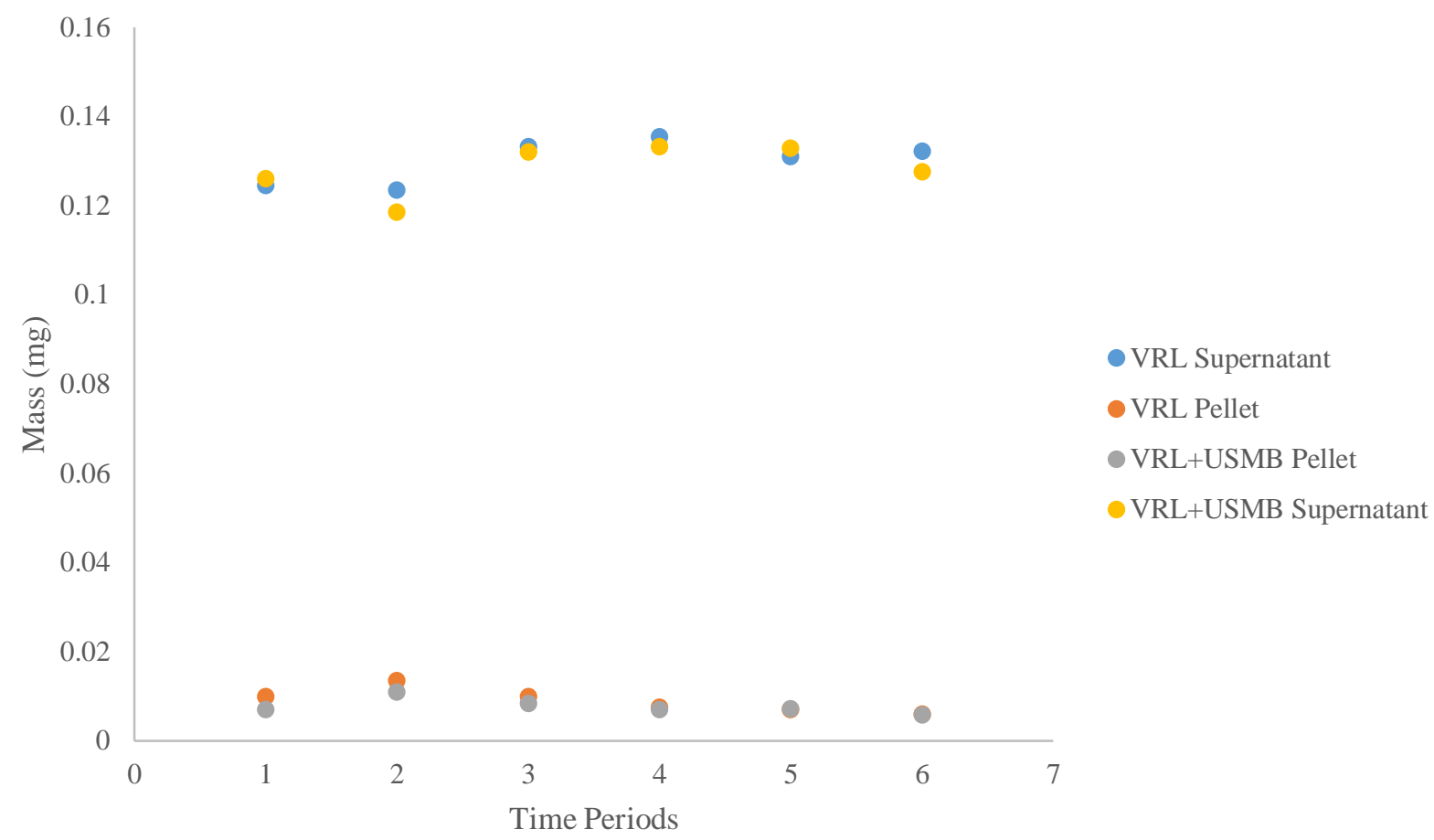

Figure 6-5 Intracellular and supernatant VRL mass of samples exposed to $100 \mu \mathrm{M}$ VRL and $700 \mathrm{KPa}$ PNP USMB as a function of increasing time where $1=5 \mathrm{~min}, 2=30 \mathrm{~min}, 3=1 \mathrm{hr}, 4=2 \mathrm{hr}, 5=3 \mathrm{hr}$, and $6=4 \mathrm{hr}$

Although conclusive evidence was not able to be drawn from these results, a foundation of methodology is set for future work. For this reason, further investigation is needed into the feasibility of VRL measurement of intracellular concentration using the HPLC system. 


\section{Bibliography}

Abratt, R. P., Brune, D., Dimopoulos, M., Kliment, J., Breza, J., Selvaggi, F. P., Oudard, S. (2004). Randomised phase III study of intravenous vinorelbine plus hormone therapy versus hormone therapy alone in hormone-refractory prostate cancer. Annals of Oncology, 1613-1621.

Berridge, M.V., Herst, P.M. Tan, A.S., (2005) Tetrazolium dyes as tools in cell biology: New insights into their cellular reduction. Biotechnology Annual Review, 11, 127-152.

Biotum (2018) XTT Cell Viability Assay Kit Retrieved from https://biotium.com/product/xttcell-viability-assay-kit/

Boucher, Y., Baxter, L. T., \& Jain, R. K. (1990). Interstitial Pressure Gradients in Tissue-isolated and Subcutaneous Tumors: Implications for Therapy1. Cancer Research, 50, 4478-4484.

Cancer Australia (2014) Classification of antineoplastic agents. Retrieved from http://edcan.org.au/edcan-learning-resources/supporting-resources/antineoplasticagents/classification

Chopra, R., Vykhodtseva, N., \& Hynynen, K. (2010). Influence of exposure time and pressure amplitude on blood-brain-barrier opening using transcranial ultrasound exposures. ACS Chemical Neuroscience, 1(5), 391-398.

Cochran, M. C., Eisenbrey, J. R., Soulen, M. C., Schultz, S. M., Ouma, R. O., White, S. B., Wheatley, M. A. (2011). Disposition of Ultrasound Sensitive Polymeric Drug Carrier in a Rat Hepatocellular Carcinoma Model. Academic Radiology, 18(11), 1341-1348.

Coussios, C. C., \& Roy, R. A. (2008). Applications of Acoustics and Cavitation to Noninvasive Therapy and Drug Delivery. Annual Review of Fluid Mechanics, 40(1), 395-420.

De Cock, I., Zagato, E., Braeckmans, K., Luan, Y., de Jong, N., De Smedt, S. C., \& Lentacker, I. (2015). Ultrasound and microbubble mediated drug delivery: acoustic pressure as determinant for uptake via membrane pores or endocytosis. Journal of Controlled Release: Official Journal of the Controlled Release Society, 197, 20-28.

De Jong, N., Bouakaz, A., \& Frinking, P. (2002). Basic acoustic properties of microbubbles. Echocardiography, 19(3), 229-240.

Debal, V., Morjani, H., Millot, J., \& Angiboust, J. (1992). Determination of vinorelbine (Navelbine) in tumour cells by high-performance liquid chromatography, Journal of Chromatography, 1, 93-99.

Deng, C. X., Sieling, F., Pan, H., \& Cui, J. (2004). Ultrasound-induced cell membrane porosity. Ultrasound in Medicine and Biology, 30(4), 519-526.

Deng, Z., Yan, F., Jin, Q., Li, F., Wu, J., Liu, X., \& Zheng, H. (2014). Reversal of multidrug resistance phenotype in human breast cancer cells using doxorubicin-liposome-microbubble complexes assisted by ultrasound. Journal of Controlled Release. 174, 109-116. 
Dimcevski, G., Kotopoulis, S., Bjånes, T., Hoem, D., Schjøt, J., Gjertsen, B. T., Gilja, O. H. (2016). A human clinical trial using ultrasound and microbubbles to enhance gemcitabine treatment of inoperable pancreatic cancer. Journal of Controlled Release, 243, 172-181.

Downing, K. H. (2000). Structural basis for the interaction of tubulin proteins and drugs that affect microtubule dynamics. Annual Review of Cell and Developmental Biology, 16, 89-111.

Dubinsky, T. J., Cuevas, C., Dighe, M. K., Kolokythas, O., \& Joo, H. H. (2008). High-intensity focused ultrasound: Current potential and oncologic applications. American Journal of Roentgenology, 190(1), 191-199.

Dumontet, C. (2000). Expert Opinion on Investigational Drugs Mechanisms of action and resistance to tubulin- binding agents Expert Opinion on Investigational Drugs tubulin-binding agents. Expert Opinion on Investigational Drugs, 9(4), 779-788.

Escoffre, J. M., Piron, J., Novell, A., \& Bouakaz, A. (2011). Doxorubicin delivery into tumor cells with ultrasound and microbubbles. Molecular Pharmaceutics, 8(3), 799-806.

Fan, Z., Kumon, R. E., \& Deng, C. X. (2014). Mechanisms of microbubble-facilitated sonoporation for drug and gene delivery. Therapeutic Delivery, 5(4), 467-486.

Fekri, F., Delos Santos, R. C., Karshafian, R., \& Antonescu, C. N. (2016). Ultrasound microbubble treatment enhances clathrin-mediated endocytosis and fluid-phase uptake through distinct mechanisms. PLoS ONE, 11(6), 1-22.

Ferguson, P. J., \& Cass, C. E. (1985). Differential Cellular Retention of Vincristine and Vinblastine by Cultured Human Promyelocytic Leukemia HL-60 / CI Cells : The Basis of Differential Toxicity. Cancer Research, 45, 5480-5488.

Gascoigne, K. E., \& Taylor, S. S. (2009). How do anti-mitotic drugs kill cancer cells? Journal of Cell Science, 122(15), 2579-2585.

Gelfand, V., \& Bershadsky, A. (1991). Microtubule Dynamics: Mechanism, Regulation, and Function. Annual Review of Cell Biology, 7, 93-116.

Giannakakou, P., Sackett, D., \& Fojo, T. (2000). Tubulin/microtubules: Still a promising target for new chemotherapeutic agents. Journal of the National Cancer Institute, 92(3), 182-183.

Goertz, D. E., Todorova, M., Mortazavi, O., Agache, V., Chen, B., Karshafian, R., \& Hynynen, K. (2012). Antitumor Effects of Combining Docetaxel (Taxotere) with the Antivascular Action of Ultrasound Stimulated Microbubbles. PLoS ONE. 7(12), 1-10

Goodman, L. S., Brunton, L. L., Chabner, B., \& Knollmann, B. C. (2011). Goodman \& Gilman's pharmacological basis of therapeutics. New York: McGraw-Hill.

Greig, N. H., Soncrant, T. T., Shetty, H. U., Momma, S., Smith, Q. R., \& Rapoport, S. I. (1990). Brain uptake and anticancer activities of vincristine and vinblastine are restricted by their low cerebrovascular permeability and binding to plasma constituents in rat. Cancer Chemotherapy and Pharmacology, 26, 263-268. 
Hassan, M. A., Furusawa, Y., Minemura, M., Rapoport, N., Sugiyama, T., \& Kondo, T. (2012). Ultrasound-Induced New Cellular Mechanism Involved in Drug Resistance. PLoS ONE, 7(12), $1-12$.

Hernot, S., \& Klibanov, A. L. (2008). Microbubbles in ultrasound-triggered drug and gene delivery. Advanced Drug Delivery Reviews, 60(10), 1153-1166.

Hobbs, S. K., Monsky, W. L., Yuan, F., Roberts, W. G., Torchilin, V. P., Jain, R. K., Jain, R. K. (1998). Regulation of Transport Pathways in Tumor Vessels : Role of Tumor Type and Microenvironment Published by : National Academy of Sciences Stable.Regulation of transport pathhways in tumor vessels: Role of tumor. Medical Sciences, 95(8), 4607-4612.

Honda, H., Kondo, T., Zhao, K.-L., Lorento, B. F., \& Kitigawa, H. (2004). Role of intracellular calcium ions and reactive oxygen species in apoptosis induced by ultrasound. Ultrasound in Medicine and Biology, 30(5), 683-692.

Ibsen, S., Schutt, C., \& Esener, S. (2013). Microbubble-mediated ultrasound therapy: a review of its potential in cancer treatment. Design, Development and Therapy, 7, 375-388.

Jackson, D. V, \& Bender, R. A. (1979). Cytotoxic Thresholds of Vincristine in a Murine and a Human Leukemia Cell Line in Vitro. Cancer Research, 39, 4346-4349.

Johnson, I. S., Wright, H. F., Svoboda, G. H., \& Vlantis, J. (1960). Antitumor Principles Derived from Vinca rosea Linn I. Vincaleukoblastine and Leurosine. Cancer Research, 20, 1016-1022.

Jordan, A., Hadfield, J. A., Lawrence, N. J., \& McGown, A. T. (1998). Anticancer Drugs : Agents Which Interact with the Mitotic Spindle. Med. Res. Rev., 18(4), 259-296.

Jordan, M. A., Thrower, D., Wilson, L., Jordan, M. A., Thrower, D., \& Wilson, L. (1991). Mechanism of Inhibition of Cell Proliferation by Vinca Alkaloids. Cancer Research, 51, 22122222.

Jordan, M. A., \& Wilson, L. (2004). Microtubules as a target for anticancer drugs. Nature Reviews. Cancer, 4(4), 253-265.

Juffermans, L. J. M., Dijkmans, P. A., Musters, R. J. P., Visser, C. A., \& Kamp, O. (2006). Transient permeabilization of cell membranes by ultrasound-exposed microbubbles is related to formation of hydrogen peroxide. American Journal of Physiology. Heart and Circulatory Physiology, 291(4), 1595-1601.

Juffermans, L. J. M., Kamp, O., Dijkmans, P. A., Visser, C. A., \& Musters, R. J. P. (2008). LowIntensity Ultrasound-Exposed Microbubbles Provoke Local Hyperpolarization of the Cell Membrane Via Activation of BKCa Channels. Ultrasound in Medicine and Biology, 34(3), 502508.

Kang, J., Wu, X., Wang, Z., Ran, H., Xu, C., Wu, J., Zhang, Y. (2010). Antitumor effect of docetaxel-loaded lipid microbubbles combined with ultrasound-targeted microbubble activation on VX2 rabbit liver tumors. Journal of Ultrasound in Medicine, 29(1), 61-70. 
Kang, S.T., \& Yeh, C.K. (2012). Ultrasound Microbubble Contrast Agents for Diagnostic and Therapeutic Applications: Current Status and Future Design. Chang Gung Medical Journal, 35(2), 125-139.

Karshafian, R., \& Almasri, F. (2010). Enhancing chemotherapy by ultrasound and microbubbles: Effect of acoustic pressure and treatment order in in vitro suspension of breast and prostate cancer cells. IEEE International Ultrasonics Symposium, IUS, 1582-1585

King, D. A., Malloy, M. J., Roberts, A. C., Haak, A., Yoder, C. C., \& Brien, W. D. O. (2010). Determination of postexcitation thresholds for single ultrasound contrast agent microbubbles using double passive cavitation detection. Journal of the Acoustical Society of America, 127(6), 3449-3455.

Kotopoulis, S., Delalande, A., Popa, M., Mamaeva, V., Dimcevski, G., Gilja, O. H., McCormack, E. (2014). Sonoporation-enhanced chemotherapy significantly reduces primary tumour burden in an orthotopic pancreatic cancer xenograft. Molecular Imaging and Biology. 16(1), 53-62.

Kotopoulis, S., Dimcevski, G., Gilja, O. H., Hoem, D., \& Postema, M. (2013). Treatment of human pancreatic cancer using combined ultrasound, microbubbles, and gemcitabine: a clinical case study. Medical Physics, 40(7), 1-9.

Krause, W. (2019). Resistance to anti-tubulin agents : From vinca alkaloids to epothilones. Cancer Drug Resistance, 2, 82-106.

Lammertink, B. H. A., Bos, C., van der Wurff-Jacobs, K. M., Storm, G., Moonen, C. T., \& Deckers, R. (2016). Increase of intracellular cisplatin levels and radiosensitization by ultrasound in combination with microbubbles. Journal of Controlled Release, 238, 157-165.

Lantheus Medical Imaging (2018) Definity Prescribing Information, Report No. 515838

Leighton, T. G. (2007). What is ultrasound? Progress in Biophysics and Molecular Biology, 93(1-3), 3-83.

Lengsfeld, A. M., Dietrich, J., \& Schultze-Maurer, B. (1982). Accumulation and release of vinblastine and vincristine by HeLa Cells : Light microscopic, cinematographic, and biochemical study. Cancer Research, 42, 3798-3805.

Lentacker, I., De Cock, I., Deckers, R., De Smedt, S. C., \& Moonen, C. T. W. (2014). Understanding ultrasound induced sonoporation: Definitions and underlying mechanisms. Advanced Drug Delivery Reviews, 72, 49-64.

Lentacker, I., Geers, B., Demeester, J., De Smedt, S. C., \& Sanders, N. N. (2010). Design and evaluation of doxorubicin-containing microbubbles for ultrasound-triggered doxorubicin delivery: cytotoxicity and mechanisms involved. Molecular Therapy: The Journal of the American Society of Gene Therapy, 18(1), 101-8. 
Levêque, D., \& Jehl, F. (1996). Clinical pharmacokinetics of vinorelbine. Clinical Pharmacokinetics, 31(3), 184-197.

Liao, Z. K., Tsai, K. C., Wang, H. T., Tseng, S. H., Deng, W. P., Chen, W. S., \& Hwang, L. H. (2012). Sonoporation-mediated anti-angiogenic gene transfer into muscle effectively regresses distant orthotopic tumors. Cancer Gene Therapy, 19(3), 171-180.

Lipsman, N., Meng, Y., Bethune, A. J., Huang, Y., Lam, B., Masellis, M., Black, S. E. (2018). Blood-brain barrier opening in Alzheimer's disease using MR-guided focused ultrasound. Nature Communications, 9(2336).

Liu, H.-L., Hua, M.-Y., Chen, P.-Y., Chu, P.-C., Pan, C.-H., Yang, H.-W., Wei, K.-C. (2010). Blood-Brain Barrier Disruption with Focused Ultrasound Enhances Delivery of Chemotherapeutic Drugs for Glioblastoma Treatment. Radiology, 255(2), 415-425.

Liu, H. L., Fan, C. H., Ting, C. Y., \& Yeh, C. K. (2014). Combining microbubbles and ultrasound for drug delivery to brain tumors: Current progress and overview. Theranostics, 4(4), 432-444.

Liu, L., Chang, S., Sun, J., Zhu, S., Yin, M., Zhu, Y., Xu, R. X. (2015). Ultrasound-mediated destruction of paclitaxel and oxygen loaded lipid microbubbles for combination therapy in ovarian cancer xenografts. Cancer Letters, 361, 147-154.

Liu, Y., Zeng, M., Liu, X., Luo, L., Yuan, Z., Xia, Y., \& Zeng, Y. (2007). Torsional mode versus conventional ultrasound mode phacoemulsification. Randomized comparative clinical study. Journal of Cataract and Refractive Surgery, 33(2), 287-292.

Lozano, R., Naghavi, M., Foreman, K., Lim, S., Shibuya, K., Aboyans, V., Murray, C. J. L. (2012). Global and regional mortality from 235 causes of death for 20 age groups in 1990 and 2010: A systematic analysis for the Global Burden of Disease Study 2010. The Lancet. 380. 2095-2128.

McDannold, N., Vykhodtseva, N., \& Hynynen, K. (2008). Blood-Brain Barrier Disruption Induced by Focused Ultrasound and Circulating Preformed Microbubbles Appears to Be Characterized by the Mechanical Index. Ultrasound in Medicine and Biology, 34(5), 834-840.

Meijering, B. D. M., Juffermans, L. J. M., Van Wamel, A., Henning, R. H., Zuhorn, I. S., Emmer, M., Kamp, O. (2009). Ultrasound and microbubble-targeted delivery of macromolecules is regulated by induction of endocytosis and pore formation. Circulation Research, 104(5), 679687.

Minchinton, A. I., \& Tannock, I. F. (2006). Drug penetration in solid tumours. Nature Reviews Cancer, 6(8), 583-592.

Mo, S., Coussios, C. C., Seymour, L., \& Carlisle, R. (2012). Ultrasound Enhanced Drug Delivery for Cancer. Expert Opinion on Drug Delivery, 9(12), 1525-1538.

Momin, S. (2016). On The Acoustic Response of Ultrasonically - Stimulated Microbubbles and Enhanced Intracellular Uptake of a Fluorescent Molecule. 
Newman, C. M. H., \& Bettinger, T. (2007). Gene therapy progress and prospects: Ultrasound for gene transfer. Gene Therapy, 14(6), 465-475.

Noble, R. L., Beer, C. T., \& Cutts, J. H. (1958). Role of chance observation in chemotherapy: vinca rosea. Annals of the New York Academy of Sciences, 76(3), 882-894.

Nomikou, N., \& Mchale, A. P. (2010). Exploiting ultrasound-mediated effects in delivering targeted, site-specific cancer therapy. Cancer Letters, 296(2), 133-143.

Oshiro, C., Marsh, S., Mcleod, H., Carrillo, M., Klein, T., \& Altman, R. (2010). Taxane Pathway. Pharmacogenet Genomics, 19(12), 979-983.

Page, R., \& Takimoto, C. (1998). Principles of chemotherapy. In R. Pazdur, L. Coia, \& W. Hoskins (Eds.), Cancer Management: A Multidisciplinary Approach. 21-37.

Poruchynsky, M. S., Wang, E. E., Rudin, C. M., Blagosklonny, M. V., \& Fojo, T. (1998). Bcl$\mathrm{x}(\mathrm{L})$ is phosphorylated in malignant cells following microtubule disruption. Cancer Research, 58(15), 3331-3338.

Postema, M., Van Wamel, A., Lancée, C. T., \& De Jong, N. (2004). Ultrasound-induced encapsulated microbubble phenomena. Ultrasound in Medicine and Biology, 30(6), 827-840.

Qin, J., Wang, T.Y., \& Willmann, J. K. (2016). Therapeutic Ultrasound. In J.M. Escoffre \& A. Bouakaz (Eds.), Therapeutic Ultrasound. 11, 357-362.

Qiu, Y., Luo, Y., Zhang, Y., Cui, W., Zhang, D., Wu, J., Tu, J. (2010). The correlation between acoustic cavitation and sonoporation involved in ultrasound-mediated DNA transfection with polyethylenimine (PEI) in vitro. Journal of Controlled Release. 145. 40-48.

Rahmani, D., Coloma, F., Placidi, M., Rahmani., R. (1994). Human Hepatic Uptake of Two Vinca Alkaloids: Navelbine and Vincristine. Journal of Pharmaceutical Sciences. 83(4), 468471.

Rowinsky, E. K., \& Donehower, R. C. (1991). The clinical pharmacology and use of antimicrotubule agents in cancer chemotherapeutics. Pharmacology and Therapeutics, 52(1), $35-84$.

Rowinsky E. (2003) The Vinca Alkaloids. In: Kufe DW, Pollock RE, Weichselbaum RR, et al., editors. Holland-Frei Cancer Medicine. 6th edition. Hamilton (ON): BC Decker;

Rubin, C., Bolander, M., Ryaby, J. P., \& Hadjiargyrou, M. (2001). The use of low-intensity ultrasound to accelerate the healing of fractures. Journal of Bone and Joint Surgery - Series A, 83(2), 259-270.

Schlicher, R., Hutcheson, J. D., Radhakrishna, H., Apkarian, R. P., \& Prausnitz, M. R. (2010). Changes in cell morphology due to plasma membrane wounding by acoustic cavitation.

Ultrasound in Medicine and Biology, 36(4), 677-692.

Scudiere, D. A., Shoemaker, R. H., Paul, K. D., Monks, A., Tierney, S., Nofziger, T. H., Boyd, M. R. (1988). Evaluation of a Soluble Tetrazolium / Formazan Assay for Cell Growth and Drug 
Sensitivity in Culture Using Human and Other Tumor Cell Lines. Cancer Research, 48, 48274833.

Shapiro, G., Wong, A. W., Bez, M., Yang, F., Tam, S., Even, L., Gazit, D. (2016).

Multiparameter evaluation of in vivo gene delivery using ultrasound-guided, microbubbleenhanced sonoporation. Journal of Controlled Release, 223, 157-164.

Simoens, C., Lardon, F., Pauwels, B., Pooter, C. M. J. De, Lambrechts, H. A. J., Pattyn, G. G. O., Vermorken, J. B. (2008). Comparative study of the radiosensitising and cell cycle effects of vinflunine and vinorelbine, in vitro. BMC Cancer, 8(65), 1-12.

Sirard, Tom (2012) Fundamentals of HPLC. Waters Corporation. Retrieved from http://www.waters.com

Sokolov, D. L., Bailey, M. R., \& Crum, L. A. (2003). Dual-pulse lithotripter accelerates stone fragmentation and reduces cell lysis in vitro. Ultrasound in Medicine and Biology, 29(7), 10451052.

Sorace, A. G., Warram, J. M., Umphrey, H., \& Hoyt, K. (2012). Microbubble-mediated ultrasonic techniques for improved chemotherapeutic delivery in cancer. Journal of Drug Targeting, 20(1), 43-54.

Sottomayor, M., \& Barcelo, A. R. (2006). The Vinca alkaloids: From biosynthesis and accumulation in plant cells, to uptake, activity and metabolism in animal cells. Studies in Natural Products Chemistry, 33, 813-857.

Stanton, R. A., Gernert, K. M., Nettles, J. H., \& Aneja, R. (2011). Drugs That Target Dynamic Microtubules: A New Molecular Perspective. Medicinal Research Reviews, 31(3), 443-481.

ter Haar, G. (2007). Therapeutic applications of ultrasound. Progress in Biophysics and Molecular Biology, 93(1-3), 111-129.

ter Haar, G., \& Coussios, C. (2007). High intensity focused ultrasound: Physical principles and devices. International Journal of Hyperthermia, 23(2), 89-104.

Timbie, K. F., Mead, B. P., \& Price, R. J. (2015). Drug and gene delivery across the blood-brain barrier with focused ultrasound. Journal of Controlled Release, 219, 61-75.

Van Wamel, A., Bouakaz, A., Versluis, M., \& De Jong, N. (2004). Micromanipulation of endothelial cells: Ultrasound-microbubble-cell interaction. Ultrasound in Medicine and Biology, 30(9), 1255-1258.

van Wamel, A., Kooiman, K., Harteveld, M., Emmer, M., ten Cate, F. J., Versluis, M., \& de Jong, N. (2006). Vibrating microbubbles poking individual cells: Drug transfer into cells via sonoporation. Journal of Controlled Release, 112(2), 149-155.

VanBavel, E. (2007). Effects of shear stress on endothelial cells: Possible relevance for ultrasound applications. Progress in Biophysics and Molecular Biology, 93(1), 374-383. 
Von Bibra, H., Voigt, J.-U., Froman, M., Bone, D., Wranne, B., \& Juhlin-Dannfeldt, A. (1999). Interaction of Microbubbles with Ultrasound. Echocardiography, 16(7), 733-741.

Wang, L. G., Liu, X. M., Kreis, W., \& Budman, D. R. (1999). The effect of antimicrotubule agents on signal transduction pathways of apoptosis: A review. Cancer Chemotherapy and Pharmacology, 44(5), 355-361.

Watanabe, Y., Aoi, A., Horie, S., Tomita, N., Mori, S., Morikawa, H., Kodama, T. (2008). Lowintensity ultrasound and microbubbles enhance the antitumor effect of cisplatin. Cancer Science, 99(12), 2525-2531.

Weaver, B. A. (2014). How Taxol/paclitaxel kills cancer cells. Molecular Biology of the Cell, 25(18), 2677-2681.

Wood, A. K. W., \& Sehgal, C. M. (2015). A review of low-intensity ultrasound for cancer therapy. Ultrasound in Medicine and Biology, 41(4), 905-928.

Wu, J., \& Nyborg, W. L. (2008). Ultrasound, cavitation bubbles and their interaction with cells. Advanced Drug Delivery Reviews, 60(10), 1103-1116.

Wu, J., Ross, J. P., \& Chiu, J.F. (2002). Reparable sonoporation generated by microstreaming. The Journal of the Acoustical Society of America, 111(3), 1460-1464.

Yan, F., Li, L., Deng, Z., Jin, Q., Chen, J., Yang, W., Zheng, H. (2013). Paclitaxel-liposomemicrobubble complexes as ultrasound-triggered therapeutic drug delivery carriers. Journal of Controlled Release, 166(3), 246-255.

Yang, S., Wang, P., Wang, X., Su, X., \& Liu, Q. (2014). Activation of microbubbles by lowlevel therapeutic ultrasound enhances the antitumor effects of doxorubicin. European Radiology, 24(11), 2739-2753.

Zeng, M., Liu, X., Liu, Y., Xia, Y., Luo, L., Yuan, Z., Liu, Y. (2008). Torsional ultrasound modality for hard nucleus phacoemulsification cataract extraction. British Journal of Ophthalmology, 92(8), 1092-1096.

Zhang, J. Z., Saggar, J. K., Zhou, Z. L., \& Bing-Hu. (2012). Different effects of sonoporation on cell morphology and viability. Bosnian Journal of Basic Medical Sciences.

Zhao, Y.Z., Du, L.N., Lu, C.T., Jin, Y.G., \& Ge, S.P. (2013). Potential and problems in ultrasound-responsive drug delivery systems. International Journal of Nanomedicine, 8, 162133.

Zhou, Y., Cui, J., \& Deng, C. X. (2008). Dynamics of sonoporation correlated with acoustic cavitation activities. Biophysical Journal, 94(7), 51-53.

Zhou, Y., Kumon, R. E., Cui, J., \& Deng, C. X. (2009). The Size of Sonoporation Pores on the Cell Membrane. Ultrasound in Medicine and Biology, 35(10), 1756-1760.

Zhou, Y., Shi, J., Cui, J., \& Deng, C. X. (2008). Effects of extracellular calcium on cell membrane resealing in sonoporation. Journal of Controlled Release, 126(1), 34-43. 
Zhou, Y., Yang, K., Cui, J., Ye, J. Y., \& Deng, C. X. (2012). Controlled permeation of cell membrane by single bubble acoustic cavitation. Journal of Controlled Release, 157(1), 103-111. 